\title{
GÊNESE E CLASSIFICAÇÃO DE SOLOS NUMA TOPOSSEQUÊNCIA NO AMBIENTE DE MAR DE MORROS DO MÉDIO VALE DO PARAÍBA DO SUL, RJ ${ }^{(1)}$
}

\author{
Adailde do Carmo Santos ${ }^{(2)}$, Marcos Gervasio Pereira ${ }^{(3)}$, Lúcia \\ Helena Cunha dos Anjos ${ }^{(3)}$, Thiago de Andrade Bernini ${ }^{(4)}$, Miguel \\ Cooper $^{(5)}$, Alexis Rosa Nummer ${ }^{(6)} \&$ Márcio Rocha Francelino ${ }^{(7)}$
}

\begin{abstract}
RESUMO
Solos tropicais são geralmente considerados altamente intemperizados, o que é atribuído às condições climáticas de altas temperaturas e precipitação pluvial. Entretanto, no ambiente de Mar de Morros, a intensidade dos processos pedogenéticos pode ser alterada pela remoção de material, em consequência do relevo movimentado, rejuvenescendo as superfícies. Este trabalho teve como objetivos caracterizar e classificar solos, formados a partir de muscovita-biotita gnaisse, em uma topossequência em Pinheiral (RJ). Os perfis localizam-se nos seguintes pontos da topossequência: (P1) topo de elevação, (P2) terço superior, (P3) terço médio, (P4) terço inferior e (P5) em área plana de várzea. Os perfis foram descritos, caracterizados e classificados segundo o Sistema Brasileiro de Classificação de Solos (SiBCS). As características edáficas que se destacaram foram: relação silte/argila; valor V \%; valor T; ki; mineralogia da fração argila; $\mathrm{e}$ formas de Fe pedogênicas de alta cristalinidade (Fed). Ao longo da topossequência encontrou-se Cambissolo Háplico Tb distrófico típico no topo e no terço médio da topossequência. No terço superior foi identificado um Argissolo Vermelho-Amarelo distrófico típico e, no terço inferior, um Argissolo Amarelo eutrófico típico. Já na
\end{abstract}

\footnotetext{
(1) Parte da Tese de Doutorado apresentada ao Curso de Pós-Graduação em Agronomia - Ciência do Solo (CPGA-CS) da Universidade Federal Rural do Rio de Janeiro - UFRRJ. Recebido para publicação em novembro de 2009 e aprovado em maio de 2010 .

(2) Doutoranda do CPGA-CS, Universidade Federal Rural do Rio de Janeiro - UFRRJ. BR 465, km 7, Seropédica, CEP $23890-000$. Rio de Janeiro (RJ). Bolsista CAPES. E-mail: adacsantos@gmail.com

(3) Professor Associado II, Departamento de Solos, UFRRJ. Bolsista CNPq e FAPERJ. E-mail: gervasio@ufrrj.br; lanjos@ufrrj.br

(4) Mestrando do CPGA-CS, UFRRJ. Bolsista do CNPq. E-mail: thiabernini@gmail.com

(5) Professor Livre Docente da Universidade de São Paulo, Escola Superior de Agricultura Luiz de Queiroz - ESALQ. Departamento de Ciência do Solo. Av Pádua Dias 11, CEP 13418-900 Piracicaba (SP).

(6) Professor Adjunto do Departamento de Geociências, UFRRJ. E-mail: nummer@ufrrj.br

(7) Professor Adjunto do Departamento de Silvicultura, UFRRJ. E-mail: marciorocha@ufrrj.br
} 


\begin{abstract}
área plana de várzea foi observado um Gleissolo Háplico Tb distrófico típico. O relevo e o material de origem gnáissico estratificado foram os principais fatores que alteram a pedogênese.
\end{abstract}

Termos de indexação: SiBCS, intemperismo, superfícies geomórficas.

\author{
SUMMARY: SOIL GENESIS AND CLASSIFICATION INTHE ENVIRONMENT \\ "MAR DE MORROS” IN THE MID-VALLEY OF THE RIVER \\ PARAIBA DO SUL, RJ
}

\begin{abstract}
Brazilian tropical soils are generally regarded as highly weathered, which is attributed to the climatic conditions (high temperatures and rainfall). However, in the "Mar de Morros" environment the intensity of pedogenic processes can be affected by the erosional removal of material, due to the hilly relief, which rejuvenates the surfaces. The objective of this study was to characterize and classify soil profiles in a toposequence developed from muscovite-biotite gneiss, located in the municipality of Pinheiral (Rio de Janeiro State). The profiles are located in different positions of a toposequence: summit (P1), shoulder (P2), backslope (P3), footslope (P4), and toeslope (P5). The profiles were described, classified and characterized according to the Brazilian System of Soil Classification (SiBCS). The differentiating soil properties were: silt/clay ratio, base saturation (V\%), T value, silica/aluminium (ki) ratio, clay fraction mineralogy, and highly crystalline pedogenic iron oxides (Fed). Along the toposequence the soils were classified as Udept in the positions summit and backslope, Udult on the shoulder and Udalf on the footslope, and Aquent in the toeslope plain. The slope position and stratified gneiss parent material were the most influential factors for pedogenesis.
\end{abstract}

Index terms : SiBCS, weathering, geomorphic surfaces.

\section{INTRODUÇÃO}

As propriedades do solo são inter-relacionadas e dependentes dos fatores de formação; logo, a variação de qualquer um dos fatores acarreta mudança nessas (Jenny, 1941). De acordo com Simonson (1959), os fatores de formação do solo controlam o processo de alteração ao longo do perfil, assim como o acúmulo e a perda decorrentes das modificações ocorridas no perfil. A partir daí surge a necessidade de conhecer a dinâmica desses fatores e seu papel na formação do solo. No entanto, como os fatores são assumidos como variáveis independentes, ainda que tenham ação conjunta durante a formação do solo, torna-se difícil uma avaliação quantitativa, e apenas uma predição qualitativa pode ser feita por meio do estudo individual de cada fator (Birkeland, 1974).

$\mathrm{O}$ material de origem influencia direta e indiretamente várias propriedades do solo. Quanto menor a intensidade do fator tempo, mais características herdadas o solo formado apresentará, e os fatores climáticos e fisiográficos exercem papel coadjuvante na pedogênese (Fanning \& Fanning, 1989). Estudando a alteração superficial e pedogeomorfológica de duas topossequências no Quadrilátero Ferrífero do Estado de Minas Gerais, Figueiredo et al. (2004) observaram na parte alta da topossequência a formação de Cambissolo e Neossolo com domínio de características herdadas da rocha gnáissica. Esse resultado comprova a atuação do material de origem em pedoambiente imaturo, onde as condições ambientais, especialmente clima e vegetação, são pouco atuantes.

O relevo é caracterizado pelo conjunto das elevações e das expressões geográficas de uma região, sendo definido pela altitude, declividade, uniformidade e extensão das superfícies (Freire, 2006). De acordo com Jenny (1941), o relevo é considerado muito mais como um agente de remoção e destruição do solo do que de formação. Segundo Buol et al. (1980), ao mesmo tempo em que o relevo modifica a influência do material de origem, tempo de remoção e deposição de material, escoamento superficial e regime do lençol freático, ele é alterado durante a pedogênese. O relevo com suas componentes recebeu especial atenção nos estudos de gênese após o surgimento da teoria da catena, formulada por Milne (1934) a partir de observações das variações dos solos ao longo da vertente. Conforme Bockheim et al. (2005), com essa teoria foi destacada a influência do relevo sobre a drenagem, movimentação vertical e horizontal da água, que pode promover alterações nos atributos do solo e favorecer a identificação de superfícies geomórficas genética e evolutivamente interdependentes. 
Troeh (1965) desenvolveu modelo de paisagem baseado na curvatura do terreno, afirmando que as feições topográficas poderiam variar entre linear, côncava e convexa, e associou a inclinação do perfil e curvatura da paisagem ao grau de intemperismo e evolução do terreno. Segundo Derruau (1965), o perfil típico de uma vertente apresenta uma convexidade no topo e uma concavidade na parte inferior, sendo ambas separadas por um simples ponto de inflexão ou segmento.

Estudando as variações das feições topográficas côncava e linear como critério para otimização amostral de Latossolo, em Jaboticabal, SP, Montanari et al. (2005) verificaram que a côncava apresentou maior variação dos atributos granulométricos, do teor de matéria orgânica e da taxa de erosão quando comparada à linear. Esse resultado confirma o padrão diferenciado dos atributos do solo em função das curvaturas do terreno. Estudando as relações solopaisagem em litossequência no município de Pereira Barreto, SP, Campos et al. (2007) observaram que os segmentos de forma côncava apresentavam valores mais elevados de soma de bases valor T e saturação por bases, que os de forma linear.

A análise de perfis de solo ao longo de uma topossequência oferece à geomorfologia dados importantes para o estudo do balanço da desnudação e dos processos dominantes na evolução das vertentes (Ghidin et al., 2006). Os vários processos (escoamento, movimento de regolito, infiltração, eluviação e outros) favorecem o fluxo de matéria e energia por meio do sistema, até que são transferidas para o sistema fluvial (Christofoletti, 1980). A vertente é um sistema complexo tridimensional que se estende do interflúvio ao meio do leito fluvial e da superfície do solo ao limite superior da rocha não intemperizada. O estudo da segmentação da vertente apresenta destacada importância para os processos que envolvem o movimento e armazenamento de água dentro do perfil do solo e, ainda, sua relação com o transporte e a deposição de sedimentos, de maneira a causar variabilidade espacial nos atributos do solo (Pachepsky et al., 2001).

Em ambiente de Mar de Morros, formado por um conjunto de colinas com diferentes graus de dissecação compreendendo toda a extensão do Planalto Atlântico, que apresentam como principais materiais de origem rochas ácidas (granitos e gnaisses), as topossequências são geralmente formadas por Latossolos, Cambissolos e Argissolos. Anjos et al. (1998), estudando solos na microbacia Caetés, em Paty do Alferes (RJ), encontraram estreita relação entre a pedogênese e superfícies geomórficas, com solos geneticamente mais evoluídos (Latossolos) nas partes altas e planas da paisagem, Cambissolos Háplicos em locais de maior perda de material e Argissolos em sítios com maior fluxo de água lateral, aliado à remoção superficial de argila.
O município de Pinheiral localiza-se no Médio Vale do Paraíba (RJ) sendo sua topografia representativa do ambiente de Mar de Morros. Na região são encontradas rochas gnáissicas e intrusões de rochas básicas (Nummer, 2001), demonstrando grande variação na composição do arcabouço geológico. Essas rochas podem ser fonte direta (solos autóctones) ou produzir sedimentos para a formação de solos em outros pontos da paisagem. Observa-se que o tipo de rocha e as diferentes posições no relevo podem interferir na direção da gênese dos solos. Assim, este trabalho teve como objetivos caracterizar os solos de uma topossequência no município de Pinheiral, RJ, formada a partir de rocha de caráter ácido (biotitamuscovita-gnaisse), e relacionar o grau de pedogênese à topografia da vertente.

\section{MATERIAL E MÉTODOS}

\section{Meio físico}

A área de estudo localiza-se no município de Pinheiral, situado na região do Médio Vale do Paraíba Fluminense, sul do Estado do Rio de Janeiro. O município abrange $81 \mathrm{~km}^{2}$ de área e está localizado entre as latitudes de $22^{\circ} 29^{\prime} 03$ " e $22^{\circ} 35^{\prime} 27^{\prime}$ " S e entre as longitudes de $43^{\circ} 54$ ' 49 " e $44^{\circ} 04$ ' 05 ” W. Está inserido na microbacia do Ribeirão do Cachimbal, que faz parte da bacia hidrográfica do Rio Paraíba do Sul (Oliveira, 1998). O clima foi definido como Cwa, com inverno seco e verão chuvoso; a precipitação pluvial anual está em torno de $1.308 \mathrm{~mm}$, e a temperatura média anual é de $20,9^{\circ} \mathrm{C}$. A geologia indica domínio das faixas de dobramentos remobilizados cuja formação deveu-se a fenômenos tectônicos. As colinas colmatadas são frequentes e fazem a interface entre graben-horst, que caracterizam o sistema Paraíba do Sul (RadamBrasil, 1983). A formação morfoestrutural explica o relevo acidentado que caracteriza a feição geomorfológica conhecida como 'Mar de Morros' (Ab'Saber, 1996) com diversos vales estruturais, que conformam uma rede de drenagem diversificada (Oliveira, 1998).

Na região há predomínio de rochas com distintos graus de metamorfismo. A área em estudo possui dois fortes domínios estruturais, caracterizados por foliação de mergulho para NW e SE. Quanto à geologia regional, Nummer (2001) subdividiu as rochas da região de Pinheiral nos seguintes litotipos: ortognaisses, biotita gnaisse, hornblenda-biotita gnaisse, granada moscovita-biotita gnaisse, milonitos e granodiorito-tonalito. Ocorrem ainda, em menor extensão, diques ou sills de diabásio, gabros e gabronoritos, não deformados, com idade provável mesozoica (Nummer, 2001). As principais rochas constituintes são os gnaisses porfiroclásticos, biotita gnaisse, muscovita biotita gnaisse e as intrusões diabásicas 
(RadamBrasil, 1983). A cobertura vegetal na área da topossequência é de floresta secundária (capoeira) e pastagens, principalmente, de Brachiaria spp.

Para o estudo, foi selecionada uma topossequência desenvolvida a partir de rocha de natureza ácida (muscovita-biotita gnaisse). Na topossequência foram abertas trincheiras em pontos distintos: topo (P1); terço superior (P2); terço médio (P3); terço inferior (P4) da encosta; e em área plana de várzea (P5). Os perfis foram descritos segundo Santos et al. (2005), coletando-se amostras deformadas e indeformadas. Durante os trabalhos de campo, também foram coletadas amostras indeformadas de horizontes selecionados dos perfis de solo, com o auxílio de caixas de papelão na dimensão de $5 \times 7 \times 10 \mathrm{~cm}$.

\section{Análises laboratoriais}

As análises químicas e físicas foram realizadas em TFSA (terra fina seca ao ar). Foram determinadas a granulometria e a densidade do solo (Ds) e das partículas $(\mathrm{Dp})$, sendo calculado a partir destas o volume total de poros do solo (VTP). Os atributos químicos analisados foram o $\mathrm{pH} \mathrm{Ca}{ }^{2+}, \mathrm{Mg}^{2+}, \mathrm{K}^{+}, \mathrm{Na}^{+}$, $\mathrm{P}, \mathrm{H}+\mathrm{Al}, \mathrm{Pe} \mathrm{C}$ orgânico. Todas as análises seguiram os métodos preconizados por Embrapa (1997).

Os teores de $\mathrm{Fe}$ na fração terra fina foram determinados por espectrofotometria de absorção atômica, após extração com solução de ditionito-citratobicarbonato de sódio (DCB), segundo Mehra \& Jackson (1960), modificado por Schulze (1984), e com solução de oxalato ácido de amônio $0,2 \mathrm{~mol} \mathrm{~L}^{-1}$, na ausência de luz, de acordo com Schwertmann (1964), e pelo ataque sulfúrico. A partir dos teores de Fe extraídos por oxalato de amônio ( $\mathrm{Feo}$ ) e ditionito-citratobicarbonato (Fed) e pelo ataque sulfúrico ( $\mathrm{Fes}$ ), foram calculadas as relações Feo/Fed e Fed/Fes, utilizadas como índice qualitativo do grau de cristalinidade dos óxidos (Kämpf, 1988) e na interpretação de processos pedogenéticos (Santos \& Batista, 1996). Além da determinação do $\mathrm{Fe}$, o ataque sulfúrico foi realizado na fração TFSA, para quantificação dos elementos alumínio, titânio e sílica no resíduo (Embrapa, 1997).

A determinação dos elementos totais via fluorescência de raios $\mathrm{X}$ foi realizada no Centro de Instrumentação Científica da Universidade de Granada. As amostras moídas de solo (0,6 g TFSA) foram previamente tratadas com $5,4 \mathrm{~g}$ de tetraborato de lítio. Essas amostras foram então aquecidas a $1.100{ }^{\circ} \mathrm{C}$ até fundirem-se e formarem pastilhas, usando prensa hidráulica Herzog e o equipamento Philips PERL'X3. As pastilhas foram analisadas em espectrômetro sequencial de longitude de onda dispersiva Philips Magix Pro (PW-2440), com gerador de raios X de ânodo $\mathrm{RH}$ operando a $4 \mathrm{kw}$ (Hallett \& Kyle, 1993) e quatro filtros de alumínio de 200 e $750 \mu$, bronze de $300 \mu$ e chumbo. O espectrômetro possui amostrador automático Philips PW2540VRC, com cinco bandejas de 12 posições, analisando 60 amostras por vez. As curvas de calibração foram obtidas com amostras-padrão. A fim de calcular as perdas de carbonato, colocou-se 1,0 g de amostra de solo para calcinar a $1.000{ }^{\circ} \mathrm{C}$ em mufla, durante $1 \mathrm{~h}$. Os resultados foram interpretados por programa analítico para análises quantitativa e semiquantitativa IQ+. Foram quantificados e são expressos em percentagem os teores de $\mathrm{SiO}_{2}, \mathrm{Al}_{2} \mathrm{O}_{3}, \mathrm{Fe}_{2} \mathrm{O}_{3}, \mathrm{TiO}_{2}, \mathrm{CaO}, \mathrm{MgO}, \mathrm{K}_{2} \mathrm{O}$, $\mathrm{Mn}, \mathrm{P}_{2} \mathrm{O}_{5}$ e Zr.

Os teores de $\mathrm{Fe}_{2} \mathrm{O}_{3}$ são identificados neste trabalho como Fef (Fe total), para indicar a quantificação pela fluorescência de raios X. Foram calculadas as relações moleculares Fed/Fef, Feo/Fed Fef/argila. Os valores de kif e krf foram determinados usando as mesmas expressões para o cálculo do ki e kr.

Os minerais da fração argila foram identificados por difração de raios X (DRX), em lâminas orientadas, montadas com suspensão de argila total $(<2,0 \mu \mathrm{m})$ obtida por sedimentação após dispersão com $\mathrm{NaOH}$ $1 \mathrm{~mol} \mathrm{~L}^{-1}$, sem eliminação de óxidos de Fe (Embrapa, 1997). As análises foram realizadas em difratômetro Bruker AXS, modelo D8 Advance, empregando-se radiação de $K \alpha$ de $\lambda 0,015405 \mathrm{~nm}$, produzida por tubo de cobre, $40 \mathrm{kv}$ e $40 \mathrm{~mA}$, com amplitude de varredura igual a $1^{\circ} 2 \theta \mathrm{min}^{-1}(0,04 \% \mathrm{~s})$. Para as amostras com indicação de presença de minerais $2: 1$, foram feitos os pré-tratamentos: aquecimento a $550{ }^{\circ} \mathrm{C}$, saturação com etilenoglicol e dimetilsulfóxido, com posterior irradiação pelos raios X. As amostras da fração areia foram previamente moídas em moinho de bolas, para obtenção do pó cristalino. Posteriormente, procedeuse à difração de raios X (DRX) em pó não orientado, sendo utilizado o mesmo equipamento empregado na identificação dos minerais da fração argila.

Quanto à análise micromorfológica, para confecção das lâminas delgadas, as amostras foram impregnadas com uma mistura de resina poliéster, monômero de estireno e pigmento fluorescente, utilizando-se peróxido metiletilcetona como catalisador para a polimerização do poliéster final e o pigmento. A laminação foi feita seguindo-se os procedimentos descritos em Murphy (1986). As lâminas foram analisadas em microscópio óptico polarizante Zeiss e com lupa binocular Wild, ambos sob luz normal e polarizada. As descrições seguiram os critérios e terminologia proposta por Brewer (1976) e Bullock et al. (1985). A análise descritiva compreendeu as seguintes etapas: (a) identificação dos constituintes do fundo matricial plasma, esqueleto e poros; (b) identificação das estruturas plásmicas e de base e as suas frequências; e (c) identificação das feições pedológicas. A sequência descrita foi repetida para cada lâmina estudada. As fotomicrografias foram feitas em câmara fotomicroscópica Zeiss do DIGEO-IPT.

A partir dos atributos morfológicos, físicos, químicos, mineralógicos e micromorfológicos, os solos foram classificados segundo o Sistema Brasileiro de Classificação de Solos - SiBCS (Embrapa, 2006). 


\section{RESULTADOS E DISCUSSÃO}

\section{Meio físico}

No perfil altimétrico (Figura 1) estão dispostas as localizações dos perfis ao longo da topossequência. No topo, onde está localizado o perfil $\mathrm{P} 1$, o relevo foi caracterizado como suave ondulado, com $7 \%$ de declividade; para o perfil P2, no terço superior, o relevo é ondulado, com $8 \%$ de declividade. Maiores valores de declividade foram verificados para o perfil P3, no terço médio, de relevo local escarpado com $116 \%$ de declividade; o perfil $\mathrm{P} 4$, no terço inferior, que se localiza em área de relevo ondulado, com $16 \%$ de declividade; e, no último ponto da topossequência, o perfil P5, que se situa em relevo plano.

\section{Atributos morfológicos}

Os dados morfológicos (Quadro 1) mostram que a cor dos solos na topossequência apresenta-se cinzaescura nos horizontes superficiais e com matizes amarelados e avermelhados nos subsuperficiais. Essas cores são decorrentes da natureza do material de origem (muscovita-biotita gnaisse), que possui pequena contribuição de minerais ferromagnesianos em sua composição. Segundo Kämpf \& Curi (2000), as condições climáticas (ambientes úmidos) características de um material de origem com baixos teores de Fe favorece a formação de goethita em detrimento da hematita, conferindo a cor amarela à matriz do solo. A concentração de óxidos de Fe está relacionada ao material de origem, ao grau de intemperização e aos processos pedogenéticos que contribuem para a acumulação ou remoção de $\mathrm{Fe}$ (Kampf \& Curi, 2000). O perfil P5, devido ao predomínio de condições de hidromorfia, apresenta cor acinzentada em todos os horizontes, à exceção do horizonte Cg3 de cor bruno-oliváceo-clara, com mosqueados nos horizontes Cg2 e Cg3. Segundo Duchaufor (1982), perfis de solos submetidos ao processo de gleização podem apresentar cores acinzentadas azuladas ou esverdeadas.

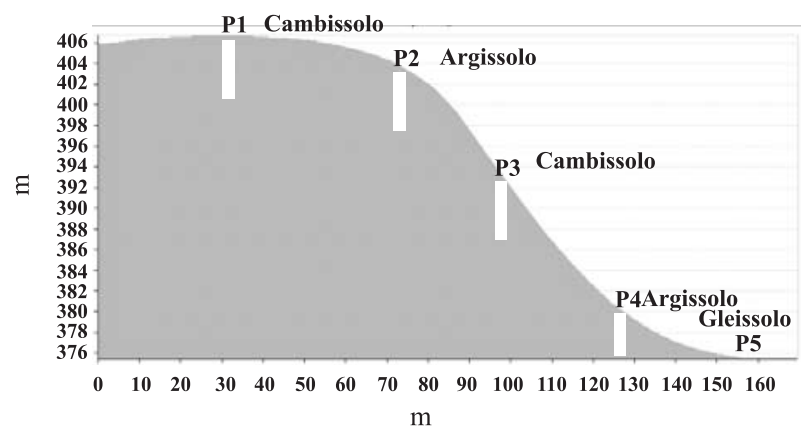

Figura 1. Perfil altimétrico da topossequência, abrangendo as formas plana, convexa, retilínea, côncava e plana, segundo a classificação de Troeh (1965).
Quanto à estrutura, nos horizontes superficiais verificam-se estruturas granulares e blocos subangulares com grau de desenvolvimento variando de moderado a forte (Quadro 1). Esses tipos de estrutura são favorecidos pela ação cimentante da matéria orgânica (Six et al., 2004) e maior atividade biológica nos horizontes superficiais. Nos horizontes subsuperficiais, a estrutura do tipo blocos subangulares e angulares, de grau moderado e forte, exceto pelo perfil P5, é proporcionada pelos maiores valores de argila em subsuperfície. Resende et al. (2005) atribuem a estrutura em blocos dos horizontes subsuperficiais dos solos à presença de caulinita associada aos baixos teores de óxidos. Estudando o efeito do material de origem e posição topográfica em solos da Baixada Sul Fluminense no Rio de Janeiro, Silva et al. (2001) também verificaram no horizonte Bt de Argissolo Vermelho-Amarelo estrutura em blocos moderadamente desenvolvida, como consequência da ação dos ciclos alternados de umedecimento e secagem, associados à mineralogia caulinítica.

Em alguns perfis observou-se revestimento dos agregados, que, em nível macromorfológico, apresentaram aspecto lustroso e brilho graxo, sendo essa feição classificada como cerosidade. Esse atributo apresentou-se em grau variável desde pouca e fraca, no perfil $\mathrm{P} 1$, até abundante e moderada, no perfil $\mathrm{P} 4$.

\section{Atributos físicos}

A análise granulométrica dos solos (Quadro 2) mostra elevados teores de areia, sendo a fração areia grossa predominante, o que resulta da maior resistência do material de origem gnáissico ao intemperismo, em função de sua composição mineralógica. A relação silte/argila foi próxima ou superior a 0,6 nos horizontes superficiais e nos horizontes $\mathrm{C}$ do perfil P1. De modo geral, todos os solos mostraram elevados valores de argila dispersa, concomitante com o baixo grau de floculação (GF), à exceção dos horizontes mais profundos dos perfis P2, P3 e P4. Um possível fator para a elevada dispersão desses solos é o teor de $\mathrm{Mg}$, que foi superior ao de Ca. Estudando atributos físicos e químicos de solos da Paraíba, Corrêa et al. (2003) observaram que o valor de argila dispersa aumentava em função do efeito dispersante promovido pelo íon $\mathrm{Mg}$. O baixo GF nos horizontes superficiais favorece a remoção seletiva das argilas e o mecanismo de translocação e, consequentemente, a elevação do gradiente textural nos perfis $\mathrm{P} 2$ e $\mathrm{P} 4$.

Os valores de Ds foram elevados, variando de 1,17 a $1,58 \mathrm{Mg} \mathrm{m}^{-3}$, associados aos maiores teores de areia. Estudando os solos da região Sul do Brasil, Giarola et al. (2002) observaram que a Ds foi positivamente correlacionada com a fração areia fina. Em profundidade, a variação da Ds está associada à diminuição dos teores de matéria orgânica, ao aumento dos percentuais de areia e silte. A Dp apresentou valores entre $2,44 \mathrm{e} 2,84 \mathrm{Mg} \mathrm{m}^{-3}$, os quais 
Quadro 1. Atributos morfológicos dos horizontes da topossequência, em Pinheiral, RJ

\begin{tabular}{|c|c|c|c|c|c|c|}
\hline \multirow[b]{2}{*}{ Hor ${ }^{(1)}$} & \multirow[b]{2}{*}{$\operatorname{Prof}^{(2)}$} & \multicolumn{2}{|c|}{ Cor úmida } & \multirow[b]{2}{*}{ Estrutura $^{(4)}$} & \multirow[b]{2}{*}{ Cerosidade $^{(5)}$} & \multirow{2}{*}{$\begin{array}{l}\text { Classe } \\
\text { textural }^{(6)}\end{array}$} \\
\hline & & Matriz & $\operatorname{Mosq}^{(3)}$ & & & \\
\hline & $\mathrm{cm}$ & & & erfil P1 & & \\
\hline $\mathrm{A} 1$ & $0-7$ & $10 \mathrm{YR} 3 / 1$ & - & mo., pq., e gr. & - & faa \\
\hline $\mathrm{A} 2$ & $7-19$ & $10 \mathrm{YR} 4 / 1$ & - & mo., me., gr. e bsa. & - & faa \\
\hline $\mathrm{BA}$ & $19-32$ & $10 \mathrm{YR} 5 / 4$ & - & mo., pq. e me., ba. e bsa. & po. e fr. & faa \\
\hline Bi1 & $32-49$ & $5 \mathrm{YR} 4 / 6$ & - & mo., pq. e me., bsa. & po. e fr. & faa \\
\hline $\mathrm{Bi} 2$ & $49-71$ & $5 Y R 4 / 6$ & - & fo., me. e bsa. & po. e fr. & argila \\
\hline $\mathrm{BC}$ & $71-90$ & $10 \mathrm{YR} 4 / 6$ & - & fr., pq., me., e bsa. & - & faa \\
\hline $\mathrm{C}$ & $90-76$ & $2,5 \mathrm{Y} 6 / 4$ & - & fr., pq. e me., bsa. & - & areia-franca \\
\hline $\mathrm{Cr}$ & $176-192$ & $2,5 \mathrm{Y} 6 / 4$ & - & $\begin{array}{l}\text { fr., mpq. e me., gr. e bsa } \\
\text { Perfil P2 }\end{array}$ & - & areia-franca \\
\hline $\mathrm{A} 1$ & $0-9$ & $10 \mathrm{YR} 4 / 1$ & - & mo., pq., gr & - & faa \\
\hline $\mathrm{A} 2$ & $9-25$ & $10 \mathrm{YR} 4 / 1$ & - & mo., pq., gr. e bsa. & - & faa \\
\hline BA & $25-63$ & $10 \mathrm{YR} 4 / 6$ & - & mo., pq. e me., ba. e. bsa & - & faa \\
\hline Bt1 & $63-112$ & $7,5 \mathrm{YR} 6 / 8$ & - & mo., pq. e me., bsa. & - & argila \\
\hline Bt2 & $112-149$ & $2,5 \mathrm{YR} 5 / 8$ & - & mo., pq., bsa. & - & muito argilosa \\
\hline Bt3 & $149-196$ & $2,5 \mathrm{YR} 5 / 6$ & - & $\begin{array}{l}\text { mo., pq., bsa. } \\
\text { Perfil P3 }\end{array}$ & - & argila \\
\hline A & 0-18 & 10YR 4/1 & - & mo., pq. e me., gr, bsa. & - & faa \\
\hline BA & $18-43$ & $7,5 \mathrm{YR} 4 / 4$ & - & mo., pq. e me., bsa. & po. e fr. & faa \\
\hline $\mathrm{Bi1}$ & $43-72$ & $7,5 \mathrm{YR} 4 / 4$ & - & fo., me. e gr., ba. e bsa. & po. e fr. & argila \\
\hline $\mathrm{Bi} 2$ & $72-103$ & $2,5 \mathrm{YR} 5 / 6$ & - & mo., pq., e me., ba. & po. e fr. & argila \\
\hline $\mathrm{Bi} 3$ & $103-200$ & 2,5YR 5/8 & - & $\begin{array}{l}\text { mo., pq. e me., ba. e bsa } \\
\text { Perfil P4 }\end{array}$ & - & faa \\
\hline A & $0-13$ & 10YR 4/1 & - & mo., mpq. e pq., gr., e bsa. & - & faa \\
\hline $\mathrm{AB}$ & $13-27$ & $10 \mathrm{YR} 4 / 2$ & - & mo., pq. e me., bsa. & - & faa \\
\hline BA & $27-57$ & $10 Y R$ 4/3 & - & mo., pq., bsa. & po. e fr. & faa \\
\hline Bt1 & $57-74$ & $7,5 \mathrm{YR} 4 / 4$ & - & fo., me. e gr., ba., e bsa. & ab. e mo. & argila \\
\hline Bt2 & $74-104$ & $7,5 \mathrm{YR} 4 / 6$ & - & mo., pq., ba. & co. e mo. & argila \\
\hline Bt3 & $104-138$ & $10 Y R 6 / 8$ & - & mo., pq. e me., ba. & co. e mo. & faa \\
\hline $\mathrm{BC}$ & $138-144$ & $10 \mathrm{YR} 6 / 6$ & - & mo., pq. e me., ba. e bsa. & co. e mo. & faa \\
\hline $\mathrm{C}$ & $144-199$ & $10 \mathrm{YR} 6 / 6$ & $\cdot$ & $\begin{array}{l}\text { mo., pq. e me., bsa. } \\
\text { Perfil P5 }\end{array}$ & - & faa \\
\hline A & $0-19$ & 10YR 3/1 & 7,5Y 5/8; po.,co. e di. & fo., pq., gr. & - & franco-arenosa \\
\hline $\mathrm{AC}$ & $19-29$ & $10 \mathrm{YR} 4 / 1$ & $7,5 \mathrm{Y} 5 / 8$; po.,co. e di. & fo., pq. e me., bsa. & - & franco-arenosa \\
\hline $\mathrm{Cg} 1$ & $29-76$ & N 5 & - & maciça & - & faa \\
\hline Cg2 & $76-105$ & $10 \mathrm{YR} 6 / 1$ & $2,5 Y$ 5/4; po.,co. e di & maciça & - & faa \\
\hline Cg3 & $105-140$ & $2,5 Y 5 / 4$ & N 5; po.,co. e di. & maçica & - & faa \\
\hline
\end{tabular}

(1) Hor: horizonte. ${ }^{(2)}$ Prof: profundidade. ${ }^{(3)}$ Mosq: mosqueado; po: pouco; co: comum; di: distinto. ${ }^{(4)}$ fr: fraca; mo: moderada; fo: forte; mpq: muito pequena; pq: pequena; me: média; ba: blocos angulares; bsa: blocos subangulares; gr: granular. ${ }^{(5)}$ po: pouco; co: comum; ab: abundante. ${ }^{(6)}$ faa: franco-argiloarenosa.

decorrem da mineralogia do material de origem, muscovita-biotita gnaisse, contribuindo com minerais como quartzo e micas.

\section{Atributos químicos}

Os atributos químicos dos solos (Quadro 3) mostram valores de $\mathrm{pH}$ em água entre 5,0 e 6,4; saturação por bases (V \%) entre 29 e $77 \%$; sendo o $\mathrm{Mg}$, seguido pelo $\mathrm{Ca}$, os principais constituintes do complexo sortivo. Em todos os solos verificam-se elevados teores de $\mathrm{Mg}$, em função do material de origem (muscovita-biotita-gnaisse), pela maior concentração deste elemento na constituição dos minerais primários, devido à substituição isomórfica do $\mathrm{Al}$ pelo $\mathrm{Mg}$, nas lâminas octaédricas de minerais micáceos (Besoain, 1985). O valor de K, ligeiramente mais elevado em superfície, está relacionado aos maiores aportes de matéria orgânica e, ou, adubação realizada na área. Os teores de C orgânico decrescem em profundidade, sendo o maior valor observado no horizonte A do perfil P1. Os mais elevados valores de $\mathrm{V} \%$ também ocorrem no perfil $\mathrm{P} 1$. Os teores de $\mathrm{P}$ são baixos em todos os solos. Os valores da CTC da argila da fração argila (Quadro 3) variam de 11,01 a $20,96 \mathrm{cmol}_{\mathrm{c}} \mathrm{kg}^{-1}$, caracterizando solos com argila de baixa atividade (CTC $<27 \mathrm{cmol}_{\mathrm{c}} \mathrm{kg}^{-1}$ argila).

No quadro 4 são apresentados os valores dos elementos totais avaliados pelo método da fluorescência de raios $\mathrm{X}$ e os valores das relações kif e krf obtidos a partir dos teores de $\mathrm{Si}, \mathrm{Al}$ e Fe (Quadro 4). Observase que, à medida que o material de origem é alterado e evolui o grau de pedogênese, nos horizontes subsuperficiais ocorrem perdas mais intensas dos teores de $\mathrm{Si}, \mathrm{Ca}, \mathrm{P}$ e $\mathrm{P}$ e aumento relativo de $\mathrm{Fe}, \mathrm{Al}$, Ti 
Quadro 2. Atributos físicos dos solos da topossequência em Pinheiral, RJ

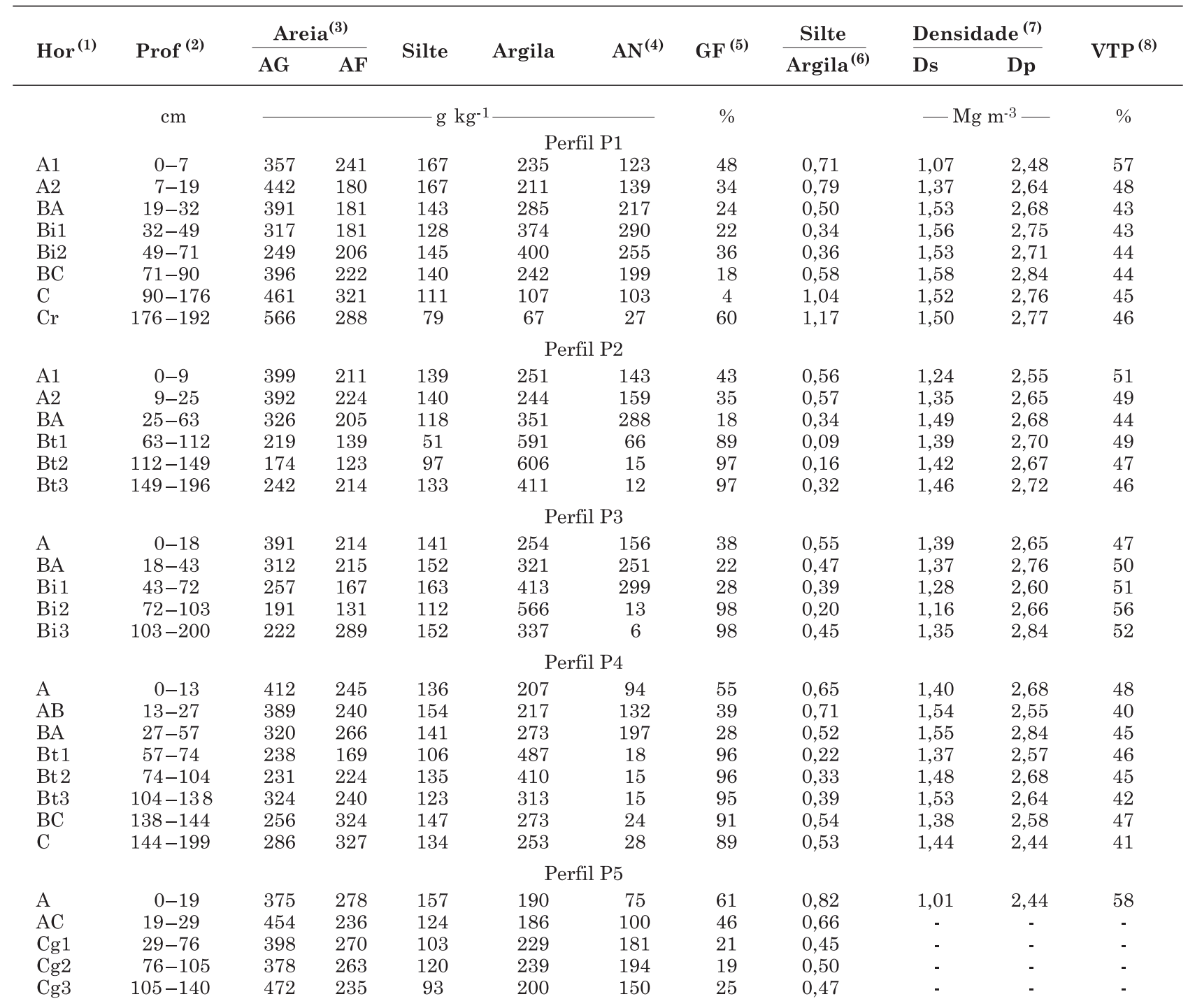

${ }^{(1)}$ Hor: horizonte. ${ }^{(2)}$ Prof: profundidade. ${ }^{(3)}$ AG: areia grossa; AF: areia fina. ${ }^{(4)} \mathrm{AN}$ : argila naturalmente dispersa em água. ${ }^{(5)}$ GF: grau de floculação. ${ }^{(6)}$ Sil/Arg: relação silte/argila. ${ }^{(7)}$ Ds: densidade do solo; Dp: densidade da partícula. ${ }^{(8)}$ VTP: porosidade total.

e Zr. Com exceção do perfil P5, localizado num ponto de paisagem que favorece a neoformação de minerais secundários e, ou, a intemperização mais lenta, os valores de kif e krf foram menores nos horizontes subsuperficiais, indicando o maior grau de intemperização dos solos.

Verifica-se a predominância do Si (570 a $820 \mathrm{~g} \mathrm{~kg}^{-1}$ $\mathrm{SiO}_{2}$ ) sobre os demais elementos (Quadro 4) em todos os perfis. Embora haja diminuição de seus valores, caracterizando perda de Si em função de alteração dos minerais primários, a resistência ao intemperismo imposta pela mineralogia do muscovita-biotita gnaisse e a seleção de frações de maior tamanho preservam altos teores de Si nos horizontes superficiais. Os teores de $\mathrm{Al}$ e $\mathrm{Fe}$ aumentam ligeiramente nos horizontes subsuperficiais, porém, em função do material de origem, os teores desses elementos são, em geral, baixos.

Observa-se o decréscimo dos valores de $\mathrm{Ca}$ em profundidade, associado ao aumento de $\mathrm{Mg}$, sugerindo a influência do mineral biotita, nos horizontes mais profundos. Os teores de K apresentam grande variação nos perfis, sendo esse o elemento de maior quantidade entre os demais, o que pode ser atribuído à elevada quantidade de muscovita na rocha de origem.

Os teores de Ti são baixos e apresentam ligeiro aumento concomitante ao incremento de argila nos horizontes subsuperficiais. Em solos do sul da Bahia, Moreau et al. (2006) também observaram em Latossolo Vermelho e Argissolo Amarelo aumento de Ti diretamente proporcional à variação de argila do horizonte A para o B; esse fato foi justificado, pelos 
Quadro 3. Atributos químicos dos solos da topossequência em Pinheiral, RJ

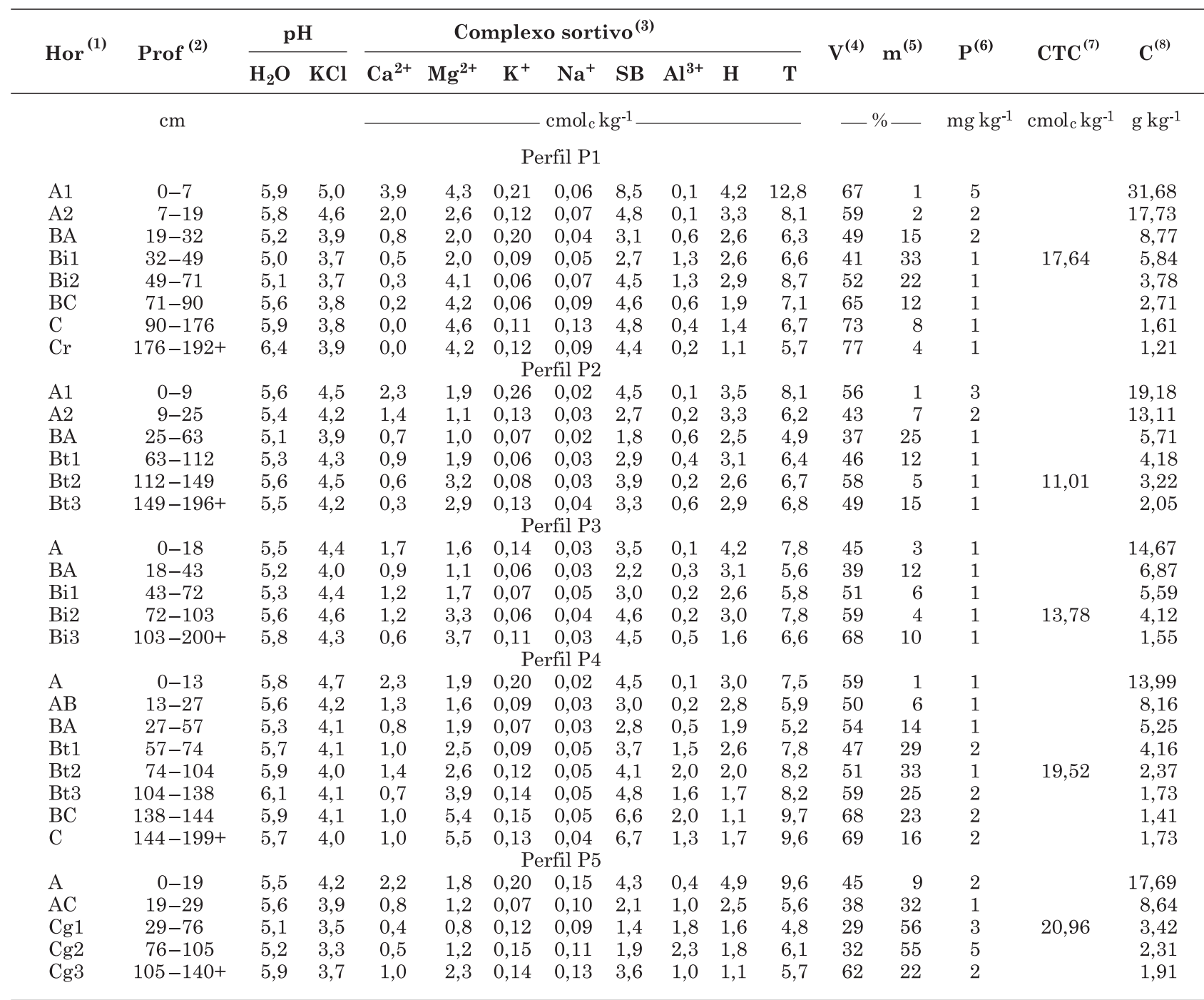

(1) Hor: horizonte. ${ }^{(2)}$ Prof: profundidade. ${ }^{(3)}$ SB: soma de bases trocáveis; T: valor T. ${ }^{(4)}$ V: saturação por bases. ${ }^{(5)}$ m: saturação por alumínio. ${ }^{(6)} \mathrm{P}$ : fósforo disponível. ${ }^{(7)} \mathrm{CTC}$ : capacidade de troca catiônica da fração argila. ${ }^{\left({ }^{8}\right)} \mathrm{C}$ : $\mathrm{C}$ orgânico total.

autores, pela baixa solubilidade e mobilidade do Ti. Tanto o Mn quanto o $\mathrm{P}$ apresentam-se relativamente uniformes e com baixos valores, o que reflete os reduzidos teores desses elementos nos minerais que constituem o gnaisse. Os valores de $\mathrm{Zr}$ foram sempre superiores nos horizontes superficiais, resultantes da maior resistência dos minerais de $\mathrm{Zr}$, sendo, portanto, seu acúmulo relativo à medida que outros elementos são removidos na superfície do solo.

Para a classificação dos perfis, segundo o SiBCS (Embrapa, 2006), os elementos Si, Al, Fe e Ti foram analisados pelo método do ataque sulfúrico e calculados os valores de ki para alguns horizontes diagnósticos subsuperficiais (Quadro 5). Os valores são inferiores aos obtidos pelo método de raios $\mathrm{X}$ por fluorescência, embora o mesmo padrão de predomínio de $\mathrm{Si}$ e baixos teores de $\mathrm{Fe}$ seja observado. A baixa relação ki indica que nos perfis localizados em áreas com melhor aeração (P1 a P4) há evolução direcionada à formação de minerais 1:1, devido às características topográficas. No perfil P5, a acumulação da sílica é favorecida pela má drenagem, com possível transformação das argilas 2:1 e neoformação de argilas 1:1.

Quanto às formas extraíveis de $\mathrm{Fe}$, com ditionitocitrato-bicarbonato (Fed) e oxalato ácido de amônio (Feo) e relações entre estas, todos os perfis apresentaram baixos teores de Fed, indicando maior contribuição de minerais primários no teor de Fe total que de óxidos de Fe pedogênicos. Segundo Kämpf \& Curi (2000), os baixos valores de Fed podem ser decorrentes da mineralogia da rocha de origem e, ou, do baixo grau de intemperismo dos solos. Neste estudo, o material de origem, muscovita-biotita gnaisse, não possui grande quantidade de minerais primários que contribuam para a formação dos óxidos pedogênicos. Estudando atributos químicos de solos do Alto Solimões 
Quadro 4. Teores de elementos quantificados pelo método do raioX por fluorescência e relações moleculares kif e krf nos solos, em Pinheiral, RJ

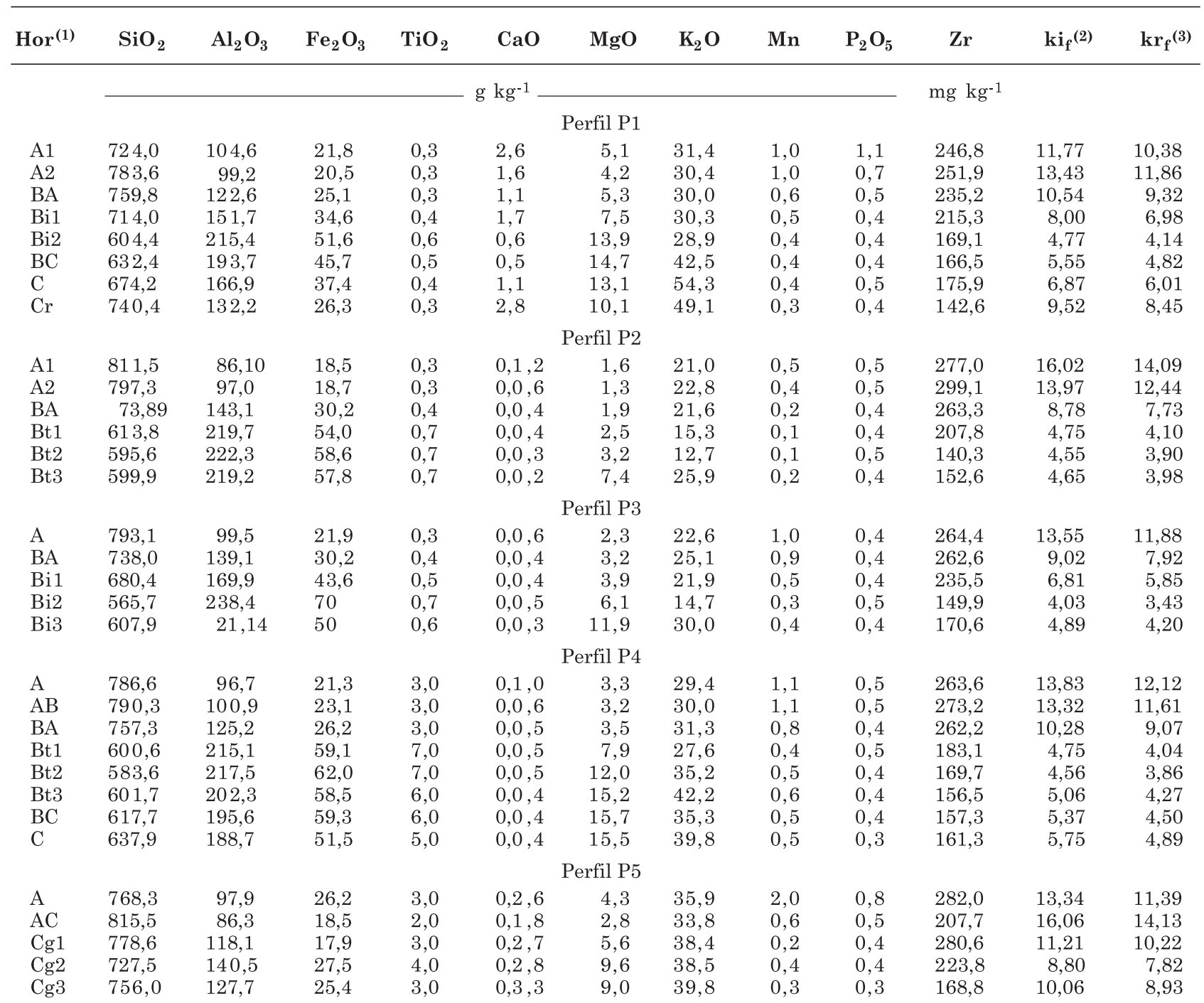

(1) Hor: horizonte. ${ }^{(2)} \mathrm{ki}_{\mathrm{f}}$ : relação molar $1,7 \mathrm{x}\left(\mathrm{SiO}_{2} / \mathrm{Al}_{2} \mathrm{O}_{3}\right)$, sendo silício e alumínio determinados por fluorescência. ${ }^{(3)} \mathrm{kr}_{\mathrm{f}}: 1,7\left(\mathrm{SiO}_{2} /\right.$ $\left.\left[\mathrm{Al}_{2} \mathrm{O}_{3}+\left(0,64 \mathrm{Fe}_{2} \mathrm{O}_{3}\right)\right]\right)$, sendo silício, alumínio e ferro determinados por fluorescência.

Quadro 5. Teores de Si, Al, Fe e Ti, determinados pelo ataque sulfúrico e relações moleculares ki e kr de horizontes selecionados dos solos da topossequência, em Pinheiral, RJ

\begin{tabular}{|c|c|c|c|c|c|c|c|}
\hline Perfil & $\operatorname{Hor}^{(1)}$ & $\mathrm{SiO}_{2}$ & $\mathrm{Al}_{2} \mathrm{O}_{3}$ & $\mathrm{Fe}_{2} \mathrm{O}_{3}$ & $\mathrm{TiO}_{2}$ & $\mathbf{k i}{ }^{(2)}$ & $\mathbf{k r}^{(3)}$ \\
\hline P1 & $\mathrm{Bi} 2$ & 178.0 & 164.0 & 50,0 & 5.5 & 1.85 & 1.54 \\
\hline P2 & Bt2 & 213,0 & 210,0 & 63,0 & 6,9 & 1,72 & 1,45 \\
\hline P3 & $\mathrm{Bi} 2$ & 203,0 & 199,0 & 640 & 6,9 & 1,73 & 1,44 \\
\hline $\mathrm{P} 4$ & Bt2 & 179,0 & 162,0 & 670 & 6,4 & 1,88 & 1,49 \\
\hline P5 & $\mathrm{Cg} 1$ & 76,0 & 57,0 & 24,0 & 3,6 & 2,27 & 1,79 \\
\hline
\end{tabular}

${ }^{(1)}$ Hor: horizonte. ${ }^{(2)}$ ki: $\left(\mathrm{SiO}_{2} / \mathrm{Al}_{2} \mathrm{O}_{3}\right)$ x 1,7. ${ }^{(3)} \mathrm{kr}:\left(\mathrm{SiO}_{2}\right.$ x 1,7$) /\left(\mathrm{Al}_{2} \mathrm{O}_{3}+\left(0,64 \times \mathrm{Fe}_{2} \mathrm{O}_{3}\right) ;\right.$ P1: topo da vertente; P2: terço superior; P3: terço médio; P4: terço inferior; $\mathrm{P} 5$ : plano de várzea.

na Amazônia, Lima et al. (2006) encontraram em Argissolo Amarelo Fed de 26 a $33 \mathrm{~g} \mathrm{~kg}^{-1}$. Em solos de ambiente de Mar de Morros, em Paty do Alferes (RJ),
Anjos et al. (1998) observaram valores de Fed variando de 14,8 a $32,4 \mathrm{~g} \mathrm{~kg}^{-1}$, com os maiores valores no horizonte $\mathrm{B}$ de Cambissolo Háplico. 
A relação Fed/Fet (Quadro 6) apresenta valores variando de 0,01 a 0,10 , menores nos horizontes $\mathrm{Ce}$ $\mathrm{Cr}$ do perfil $\mathrm{P} 1$, sugerindo que o $\mathrm{Fe}$ presente no sistema encontra-se na constituição de minerais primários, em especial da biotita. Os valores da relação Feo/Fed decrescem em profundidade, exceto para o perfil P5, localizado em condições de menor aeração, indicando que os óxidos pedogênicos de maior cristalinidade encontram-se nos horizontes diagnósticos subsuperficiais, relacionados ao incremento dos teores de argila, que decrescem em profundidade. O teor de C orgânico, elevado nos horizontes superficiais, explica os teores mais elevados de compostos de Fe de baixa cristalinidade e a maior

Quadro 6. Relações Fed/Fet, Feo/Fed e Fef/argila para os perfis da topossequência, em Pinheiral, RJ

\begin{tabular}{|c|c|c|c|c|}
\hline $\operatorname{Hor}^{(1)}$ & $\operatorname{Fed}^{(2)}$ & Fed/ Fet ${ }^{(3)}$ & Feo/Fed ${ }^{(4)}$ & Fef/argila ${ }^{(5)}$ \\
\hline \multicolumn{5}{|c|}{ Perfil P1 } \\
\hline A1 & 1,4 & 0,06 & 0,87 & 0,09 \\
\hline $\mathrm{A} 2$ & 1,4 & 0,07 & 0,90 & 0,10 \\
\hline BA & 1,4 & 0,05 & 0,91 & 0,09 \\
\hline Bi1 & 1,7 & 0,05 & 0,71 & 0,09 \\
\hline $\mathrm{Bi} 2$ & 1,9 & 0,04 & 0,61 & 0,13 \\
\hline $\mathrm{BC}$ & 0,9 & 0,02 & 0,48 & 0,19 \\
\hline $\mathrm{C}$ & 0,5 & 0,01 & 0,28 & 0,35 \\
\hline $\mathrm{Cr}$ & 0,3 & 0,01 & 0,24 & 0,39 \\
\hline \multicolumn{5}{|c|}{ Perfil P2 } \\
\hline A1 & 1,7 & 0,09 & 0,86 & 0,07 \\
\hline $\mathrm{A} 2$ & 1,6 & 0,09 & 0,90 & 0,08 \\
\hline $\mathrm{BA}$ & 1,9 & 0,06 & 0,70 & 0,09 \\
\hline Bt1 & 4,7 & 0,09 & 0,16 & 0,09 \\
\hline Bt2 & 6,1 & 0,10 & 0,13 & 0,10 \\
\hline Bt3 & 4,4 & 0,08 & 0,15 & 0,14 \\
\hline \multicolumn{5}{|c|}{ Perfil P3 } \\
\hline A & 1,7 & 0,08 & 0,81 & 0,09 \\
\hline $\mathrm{BA}$ & 2,3 & 0,08 & 0,57 & 0,09 \\
\hline Bi1 & 4,0 & 0,09 & 0,23 & 0,11 \\
\hline $\mathrm{Bi} 2$ & 6,9 & 0,11 & 0,12 & 0,12 \\
\hline $\mathrm{Bi} 3$ & 3,3 & 0,06 & 0,18 & 0,16 \\
\hline \multicolumn{5}{|c|}{ Perfil P4 } \\
\hline A & 1,9 & 0,09 & 0,75 & 0,10 \\
\hline $\mathrm{AB}$ & 2,0 & 0,09 & 0,69 & 0,11 \\
\hline $\mathrm{BA}$ & 2,4 & 0,09 & 0,51 & 0,10 \\
\hline Bt1 & 2,0 & 0,03 & 0,61 & 0,12 \\
\hline Bt2 & 3,1 & 0,05 & 0,34 & 0,15 \\
\hline Bt3 & 3,7 & 0,06 & 0,25 & 0,19 \\
\hline $\mathrm{BC}$ & 3,2 & 0,05 & 0,33 & 0,22 \\
\hline $\mathrm{C}$ & 2,2 & 0,04 & 0,40 & 0,20 \\
\hline \multicolumn{5}{|c|}{ Perfil P5 } \\
\hline A & 1,9 & 0,07 & 0,22 & 0,14 \\
\hline $\mathrm{AC}$ & 1,6 & 0,09 & 0,25 & 0,10 \\
\hline $\mathrm{Cg} 1$ & 1,4 & 0,08 & 0,69 & 0,08 \\
\hline Cg2 & 1,1 & 0,04 & 0,85 & 0,12 \\
\hline Cg3 & 1,4 & 0,05 & 0,30 & 0,13 \\
\hline
\end{tabular}

(1) Horizonte. ${ }^{(2)}$ Ferro extraído com ditionito-citrado-bicarbonato. ${ }^{(3)}$ Relação ferro extraído com ditionito-citrado-bicarbonato/ferro determinado pelo ataque sulfúrico. ${ }^{(4)}$ Relação Ferro extraído com solução de oxalato de amônio/extraído com ditionito-citrado-bicarbonato. ${ }^{(5)}$ Relação ferro determinado por fluorescência/teor de argila. relação Feo/Fed em superfície nos solos bem drenados, visto que a matéria orgânica pode inibir a cristalização do Fe (Schwertmann, 1964; Schwertmann \& Taylor, 1989). Observando os valores Fed nos perfis P1 e P3, constata-se que o aumento coincide com os teores mais elevados de argila no perfil, sugerindo a migração do óxido em conjunto com a argila. Esse padrão pode ser melhor observado por meio da pequena variação da relação Fef/argila no perfil. Estudando formas de Fe em solos de várias regiões do Brasil, Valladares (2000) observou pequena variação dessa relação em profundidade para os perfis de solo, indicando migração do Fe juntamente com a fração argila. Analisando perfis de solos de ambiente de Mar de Morros, em Paty do Alferes (RJ), Anjos et al (1998) verificaram valores da relação Fed/argila variando entre 0,033 e 0,095. Os baixos valores dessa relação, segundo os autores, indicam a menor liberação de Fe dos minerais primários e o menor grau de pedogênese dos perfis.

Os valores da relação Fef/argila nos perfis da topossequência (Quadro 6) aumentam em profundidade, sobretudo no perfil $\mathrm{P} 1$, sendo um reflexo do aumento do conteúdo de argila e de minerais primários, provenientes inclusive das frações areia e silte, uma vez que os horizontes $\mathrm{C}$ e $\mathrm{Cr}$ do perfil $\mathrm{P} 1$ apresentam menores teores de argila.

\section{Mineralogia da fração areia}

A mineralogia da fração areia (Figura 2) indica o quartzo como mineral predominante na fração areia. Também se observa a presença de feldspatos, principalmente os potássicos e traços de muscovita, confirmando a hipótese de solos com baixo grau de evolução. Pode-se também constatar que os picos mais intensos de feldspatos ocorrem nos perfis P1, P4 e P5, sugerindo maiores teores relativos desse mineral, nos solos localizados no topo e nas partes mais baixas da topossequência (terço inferior e plano de várzea). Esse fato sugere menor grau de evolução destes solos em comparação aos demais da sequência. Os valores dos elementos totais mostra teores mais elevados de $\mathrm{K}$ nesses perfis, o que é concordante com os picos mais intensos de feldspatos potássicos, verificados na mineralogia.

\section{Mineralogia da fração argila}

Em todos os horizontes diagnósticos subsuperficiais dos perfis, o principal mineral identificado nos difratogramas de raios $\mathrm{X}$ da fração argila foi a caulinita seguida pela illita, esta em menor proporção (Figura 3), mesmo nos solos com menor desenvolvimento pedogenético (P1 e P3). A presença da illita na fração argila dos perfis, assim como de montmorilonita no perfil $\mathrm{P} 5$, foi atribuída à natureza do material de origem (muscovita-biotita-gnaisse). A formação de montmorilonita é favorecida pela baixa declividade e pior drenagem na planície de inundação onde se situa o perfil P5. Neste ponto, os processos de neoformação ou de transformação das micas contri- 

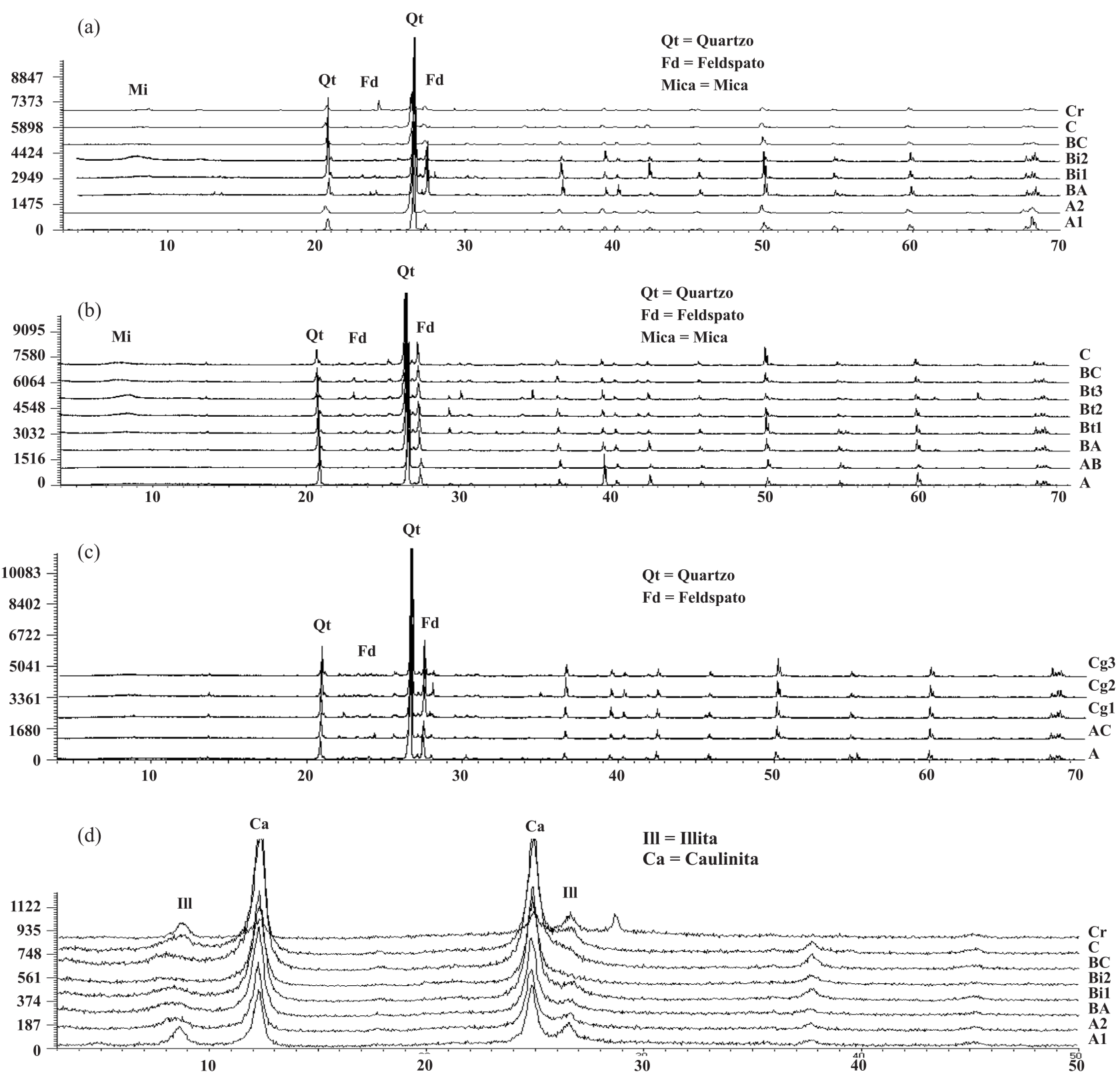

Figura 2. Difratogramas de raios X da fração areia do Cambissolo Háplico (P1) (a); fração areia do Argissolo Amarelo (P4) (b); fração areia do Gleissolo Háplico (P5) (c); fração argila do Cambissolo Háplico (P1) (d).

buem para a gênese de mineral de argila secundária (Kämpf \& Curi, 2003).

Resultados semelhantes foram encontrados por Moreira (2000), estudando atributos mineralógicos de solos da Chapada do Apodi em Fortaleza, no Estado do Ceará, constatou em Cambissolo predomínio de caulinita em relação à mica. Analisando solos de topossequências em Paty do Alferes (RJ), Anjos et al. (1998) encontraram na fração argila de Cambissolos o predomínio da caulinita e ocorrência comum de micas - padrão atribuído ao material de origem gnáissico.

Nos perfis P2, P3 e P4, onde a topografia contribui para melhor aeração do solo e alteração do material de origem, foi identificada a presença de goethita. Esse fato está de acordo com o ambiente de formação, clima úmido, e os baixos teores de Fe no material de origem (gnaisse). Nesses perfis, a relação kr é ligeiramente menor e o horizonte B diagnóstico apresenta os menores valores da relação $\mathrm{Feo} / \mathrm{Fed}$, indicando o predomínio de óxidos pedogênicos de maior cristalinidade.

\section{Micromorfologia}

A descrição micromorfológica dos horizontes selecionados é apresentada no quadro 7 e na figura 3. As fotomicrografias foram obtidas com luz XPL (polarizador e analisador) e PPL (polarizador). 

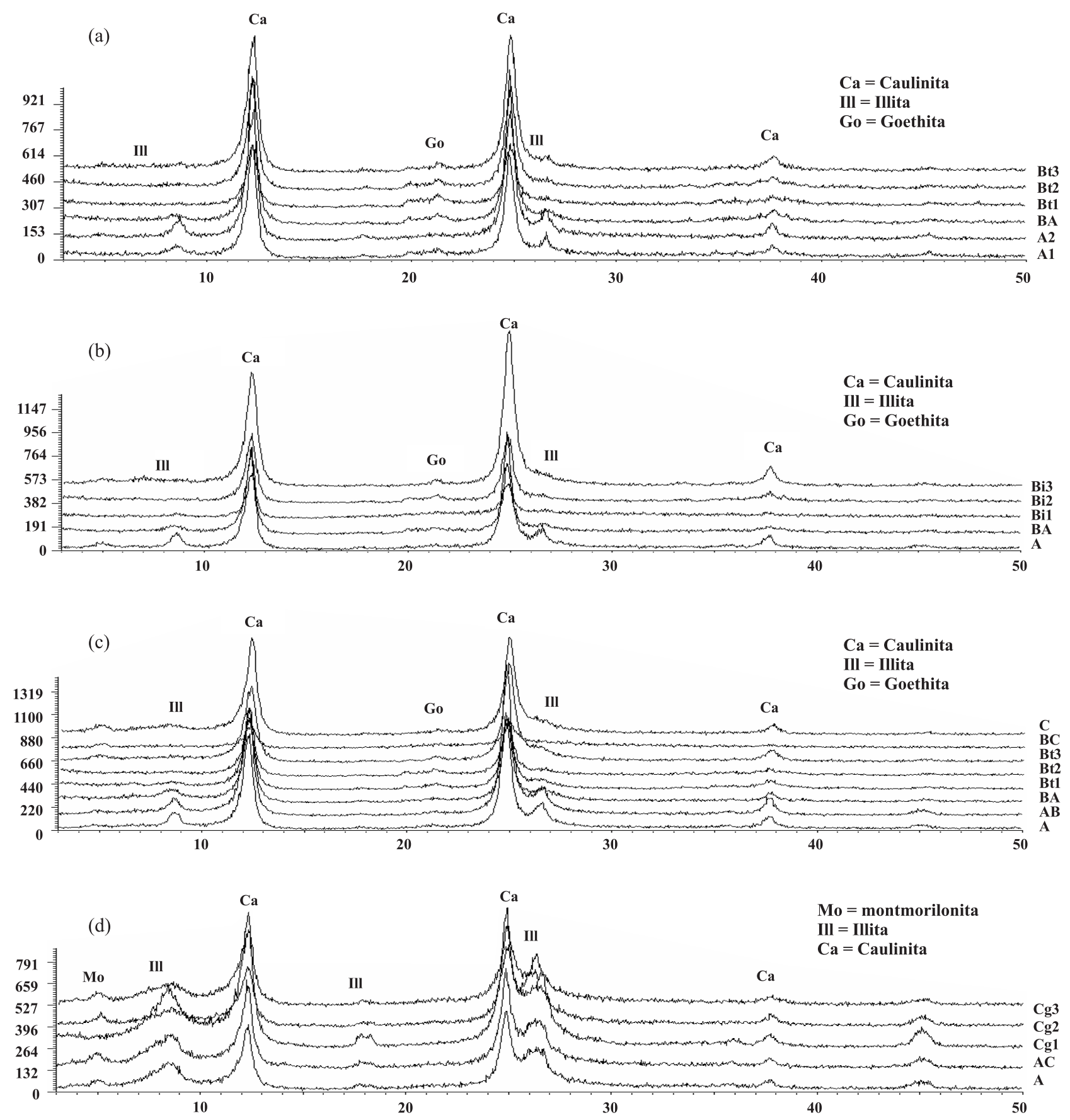

Figura 3. Difratogramas de raios X da fração argila do Argissolo Vermelho (P2) (a); fração argila do Cambissolo Háplico (P3) (b); fração argila do Argissolo Amarelo (P4) (c); fração argila do Gleissolo Háplico (P5) (d).

Os horizontes apresentaram esqueleto distribuído aleatoriamente, constantemente envolvido por argilãs de estresse, com predomínio de micas, principalmente a muscovita, com grau de alteração entre 2 e $25 \%$; e feldspatos (feldspatos potássicos e plagiocásios cálciosódicos) e com menor frequência e maior grau de alteração, entre 25 e $72 \%$. Acredita-se que a mica encontrada na massa do solo, provavelmente, seja herdada do material de origem.
Observando a micrografia do horizonte Bi1 do perfil P1 (Figuras 4, 5 e 6), constata-se que a alteração dos minerais primários contribui para dissolução e consequente formação da porosidade cavitária, resultando em uma trama mais aberta e porosidade característica do processo de intemperismo. Estudando solos derivados de rochas ultramáficas no sudoeste de Minas Gerais, Vidal-Torrado et al. (2006) verificaram em horizonte Bi trama dominante porfírica, com ma- 
Quadro 7. Descrição micromorfológica dos horizontes selecionados dos solos das topossequências

\begin{tabular}{|c|c|c|c|c|c|c|}
\hline Hor $^{(1)}$ & $\begin{array}{c}\text { Grãos } \\
\text { minerais }^{(2)}\end{array}$ & $\operatorname{PDR}^{(3)}$ & Contextura ${ }^{(2)}$ & Microestrutura & Poros & Pedofeições ${ }^{(4)}$ \\
\hline \multicolumn{7}{|c|}{ Perfil P1 } \\
\hline $\mathrm{BA}$ & $\begin{array}{l}\text { Comuns } \\
\text { feldspatos e } \\
\text { mica, } \\
\text { dominante } \\
\text { quartzo. }\end{array}$ & $\begin{array}{l}\text { Porfírica de } \\
\text { espaçamento } \\
\text { simples. }\end{array}$ & $\begin{array}{l}\text { Poroestriada e } \\
\text { granoestriada com } \\
\text { forte orientação, } \\
\text { dominante. }\end{array}$ & $\begin{array}{l}\text { Blocos angulares } \\
\text { fortemente } \\
\text { desenvolvidos. }\end{array}$ & Cavidades. & $\begin{array}{l}\text { Raros nódulos ferruginosos } \\
\text { típicos. }\end{array}$ \\
\hline Bi1 & $\begin{array}{l}\text { Comuns } \\
\text { feldspatos, } \\
\text { poucos } \\
\text { quartzos, muito } \\
\text { dominantes } \\
\text { micas. }\end{array}$ & $\begin{array}{l}\text { Porfírica } \\
\text { fechada. }\end{array}$ & $\begin{array}{l}\text { Poroestriada e } \\
\text { granoestriada com } \\
\text { forte orientação, } \\
\text { dominante. }\end{array}$ & Cavidades. & $\begin{array}{l}\text { Cavidades e } \\
\text { alguns } \\
\text { planares. }\end{array}$ & Não foram observadas. \\
\hline $\mathrm{Bi} 2$ & $\begin{array}{l}\text { Comuns } \\
\text { feldspatos e } \\
\text { quartzo, } \\
\text { dominantes } \\
\text { micas. }\end{array}$ & $\begin{array}{l}\text { Porfírica } \\
\text { fechada. }\end{array}$ & $\begin{array}{l}\text { Poroestria da e } \\
\text { granoestriada com } \\
\text { forte orientação, } \\
\text { dominante. }\end{array}$ & Cavitária. & $\begin{array}{l}\text { Cavidades e } \\
\text { alguns } \\
\text { planares. }\end{array}$ & $\begin{array}{l}\text { Raros preenchimentos } \\
\text { densos de argila, raros } \\
\text { poucos nódulos } \\
\text { ferruginosos típicos. }\end{array}$ \\
\hline \multicolumn{7}{|c|}{ Perfil P2 } \\
\hline $\mathrm{A} 2$ & $\begin{array}{l}\text { Comuns } \\
\text { feldspatos e } \\
\text { quartzo. }\end{array}$ & $\begin{array}{l}\text { Porfírica de } \\
\text { espaçamento } \\
\text { simples. }\end{array}$ & $\begin{array}{l}\text { Aleatória com fraca } \\
\text { orientação, pouca. }\end{array}$ & Cavitária. & $\begin{array}{l}\text { Cavidades e } \\
\text { alguns } \\
\text { planares. }\end{array}$ & $\begin{array}{l}\text { Ocasionais nódulos } \\
\text { ferruginosos típico. }\end{array}$ \\
\hline Bt1 & $\begin{array}{l}\text { Comuns } \\
\text { feldspatos e } \\
\text { quartzos, } \\
\text { poucas micas. }\end{array}$ & $\begin{array}{l}\text { Porfírica de } \\
\text { espaçamento } \\
\text { simples. }\end{array}$ & $\begin{array}{l}\text { Aleatória e } \\
\text { paraleloestriada } \\
\text { com forte } \\
\text { orientação, } \\
\text { dominant e. }\end{array}$ & $\begin{array}{l}\text { Blocos angulares } \\
\text { fortemente } \\
\text { desenvolvidos. }\end{array}$ & $\begin{array}{l}\text { Planares e } \\
\text { algumas } \\
\text { cavidades. }\end{array}$ & $\begin{array}{l}\text { Ocasionais revestimentos } \\
\text { de argila típicos e } \\
\text { crescentes, raros } \\
\text { preenchimentos densos de } \\
\text { argila, poucos nódulos } \\
\text { ferruginosos típicos, } \\
\text { ocasionais pápulas. }\end{array}$ \\
\hline Bt2 & $\begin{array}{l}\text { Comuns } \\
\text { feldspatos e } \\
\text { quartzos, } \\
\text { poucas micas. }\end{array}$ & $\begin{array}{l}\text { Porfírica de } \\
\text { espaçamento } \\
\text { simples. }\end{array}$ & $\begin{array}{l}\text { Aleatória e } \\
\text { paraleloestriada } \\
\text { com forte } \\
\text { orientação, } \\
\text { dominante. }\end{array}$ & $\begin{array}{l}\text { Blocos angulares } \\
\text { fortemente } \\
\text { desenvolvidos. }\end{array}$ & $\begin{array}{l}\text { Planares e } \\
\text { algumas } \\
\text { cavidades. }\end{array}$ & $\begin{array}{l}\text { Ocasionais revestimentos } \\
\text { de argila típicos e } \\
\text { crescentes, raros } \\
\text { preenchimentos densos de } \\
\text { argila, ocasionais nódulos } \\
\text { ferruginosos típicos e } \\
\text { pápulas. }\end{array}$ \\
\hline \multicolumn{7}{|c|}{ Perfil P3 } \\
\hline Bi1 & $\begin{array}{l}\text { Comuns } \\
\text { feldspatos e } \\
\text { quartzos, } \\
\text { frequentes } \\
\text { micas. }\end{array}$ & $\begin{array}{l}\text { Porfírica de } \\
\text { espaçamento } \\
\text { simples. }\end{array}$ & $\begin{array}{l}\text { Aleatória e } \\
\text { granoestriada com } \\
\text { forte orientação, } \\
\text { dominante. }\end{array}$ & Cavitária. & $\begin{array}{l}\text { Cavidades e } \\
\text { alguns } \\
\text { planares. }\end{array}$ & $\begin{array}{l}\text { Ocasionais revestimentos de } \\
\text { argila típicos, ocasionais } \\
\text { preenchimentos densos de } \\
\text { argila com ferro e silte, } \\
\text { ocasionais nódulos } \\
\text { ferruginosos típicos, muitas } \\
\text { pápulas. }\end{array}$ \\
\hline $\mathrm{Bi} 2$ & $\begin{array}{l}\text { Comuns } \\
\text { feldspatos e } \\
\text { quartzos, } \\
\text { dominante } \\
\text { micas. }\end{array}$ & $\begin{array}{l}\text { Porfírica } \\
\text { fechada. }\end{array}$ & $\begin{array}{l}\text { Aleatória e } \\
\text { paraleloestriada } \\
\text { com forte } \\
\text { orientação, comum. }\end{array}$ & $\begin{array}{l}\text { Blocos angulares e } \\
\text { subangulares } \\
\text { fortemente } \\
\text { desenvolvidos. }\end{array}$ & $\begin{array}{l}\text { Planares e } \\
\text { alguns } \\
\text { planares. }\end{array}$ & $\begin{array}{l}\text { Ocasionais revestimentos de } \\
\text { argila típicos, ocasionais } \\
\text { preenchimentos densos de } \\
\text { argila com silte, poucos } \\
\text { nódulos ferruginosos típicos, } \\
\text { muitas pápulas. }\end{array}$ \\
\hline \multicolumn{7}{|c|}{ Perfil P4 } \\
\hline BA & $\begin{array}{l}\text { Comuns } \\
\text { feldspatos e } \\
\text { quartzos, } \\
\text { ocasionais } \\
\text { micas. }\end{array}$ & $\begin{array}{l}\text { Porfírica de } \\
\text { espaçamento } \\
\text { simples. }\end{array}$ & $\begin{array}{l}\text { Aleatória e } \\
\text { granoestriada com } \\
\text { forte orientação, } \\
\text { dominante. }\end{array}$ & Cavitária. & $\begin{array}{l}\text { Cavidades e } \\
\text { alguns } \\
\text { planares. }\end{array}$ & $\begin{array}{l}\text { Raros revestimentos de argila } \\
\text { típicos, ocasionais } \\
\text { preenchimentos densos de } \\
\text { argila com silte, poucos } \\
\text { nódulos ferruginosos típicos, } \\
\text { raras pápulas. }\end{array}$ \\
\hline Bt 1 & $\begin{array}{l}\text { Comuns } \\
\text { feldspatos, } \\
\text { quartzos e } \\
\text { micas. }\end{array}$ & $\begin{array}{l}\text { Porfírica de } \\
\text { espaçamento } \\
\text { simples. }\end{array}$ & $\begin{array}{l}\text { Aleatória e } \\
\text { granoestriada com } \\
\text { forte orientação, } \\
\text { dominante. }\end{array}$ & $\begin{array}{l}\text { Blocos angulares e } \\
\text { subangulares } \\
\text { fortemente } \\
\text { desenvolvidos. }\end{array}$ & $\begin{array}{l}\text { Planares e } \\
\text { alguns } \\
\text { planares. }\end{array}$ & $\begin{array}{l}\text { Ocasionais revestimentos de } \\
\text { argila e ferro típicos, } \\
\text { ocasionais nódulos } \\
\text { ferruginosos típicos, raras } \\
\text { pápulas. }\end{array}$ \\
\hline Bt2 & $\begin{array}{l}\text { Comuns } \\
\text { feldspatos e } \\
\text { quartzos, } \\
\text { dominantes } \\
\text { micas. }\end{array}$ & $\begin{array}{l}\text { Porfírica } \\
\text { fechada. }\end{array}$ & $\begin{array}{l}\text { Aleatória e } \\
\text { granoestriada com } \\
\text { forte orientação, } \\
\text { comum. }\end{array}$ & $\begin{array}{l}\text { Blocos angulares e } \\
\text { subangulares } \\
\text { fortemente } \\
\text { desenvolvidos. }\end{array}$ & $\begin{array}{l}\text { Planares e } \\
\text { alguns } \\
\text { planares. }\end{array}$ & $\begin{array}{l}\text { Ocasionais revestimentos de } \\
\text { argila típicos. }\end{array}$ \\
\hline
\end{tabular}

(1) Horizonte. ${ }^{(2)}$ muito pouco: < $5 \%$; pouco: 5 a $15 \%$; frequente: 15 a $30 \%$; comum: 30 a $50 \%$; dominante: 50 a $70 \%$. ${ }^{(3)}$ Padrão de distribuição relacionado. ${ }^{(4)}$ Raros: $2 \%$; ocasionais: 2 a $5 \%$; muitos: 5 a $10 \%$; abundante: 10 a $20 \%$; muito abundante: $>20 \%$. 


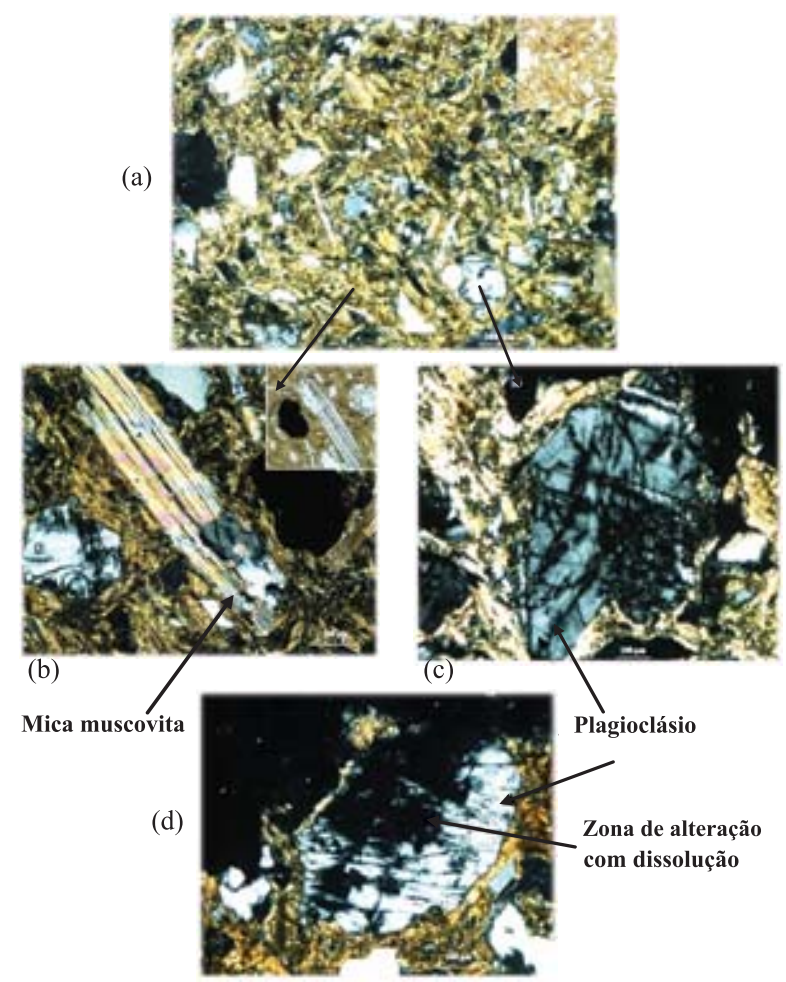

Figura 4. Fotomicrografias (XPL) do horizonte Bi1 do perfil P1, com detalhes sob luz PPL: (a) fundo matricial recoberto por mica, principalmente muscovita, com trama porfírica fechada; (b) aumento do fundo matricial, com mica e feldspatos potássicos aprisionados no plasma; (c) plagioclásio cálcio-sódico com áreas de alteração; (d) estádio mais avançado de alteração do plagioclásio.

teriais que foram submetidos a um processo de dissolução, e, como consequência, o surgimento de cavidades e intercomunicação entre estas, passando a uma trama porfírica aberta por coalescência de cavidades.

A distribuição relacionada da massa basal, para todos os solos, apresenta trama porfírica variando de espaçamento duplo, espaçamento simples, espaçamento duplo e fechada. No horizonte BA do perfil P4, verificou-se distribuição porfírica de espaço simples, na qual o material grosseiro, o quartzo, feldspatos e mica permanecem mergulhados no plasma denso e encontramse separados por uma distância equivalente ao seu tamanho (Figura 6). Em profundidade (horizonte Bt1) a contextura porfírica é de espaço simples, entretanto observou-se maior ocorrência de micas (Figura 6). No horizonte mais profundo (Bt2) constata-se a maior presença de micas, que favorecem a formação de uma trama porfírica fechada, na qual os grãos da fração grosseira estão em contato entre si.

Com o fundo matricial totalmente tomado pela mica, a observação da argila iluvial (argilãs de iluviação) e da fábrica birrefringente (argilãs de

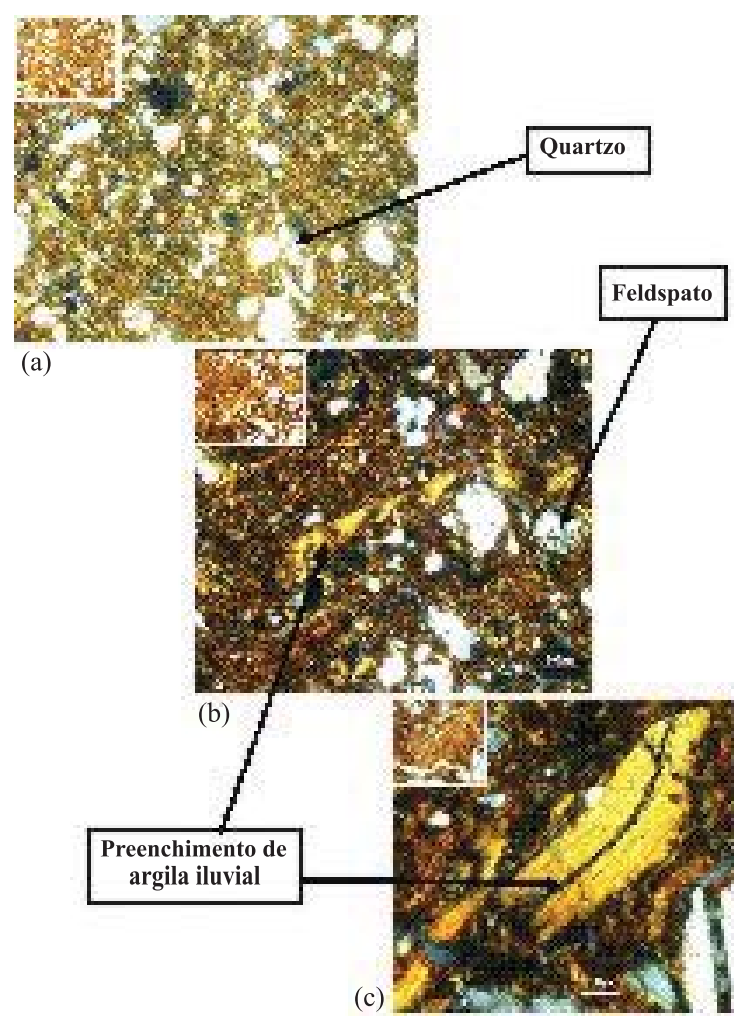

Figura 5. Fotomicrografias (XPL) do horizonte Bi1 do perfil P3, com detalhes sob luz PPL: (a) fundo matricial composto por mica incorporada ao plasma e grãos de quartzo e feldspatos potássicos; (b) preenchimento denso de argila iluvial, com orientação moderada; (c) preenchimento iluvial fragmentado (pápulas), com forte orientação.

estresse) fica dificultada, porém pode-se constatar a contextura da birrefringência aleatória, poroestriada e granoestriada, com forte desenvolvimento, com ocorrência dominante (50 a $70 \%$ ). A contextura poro ou granoestriada está relacionada à reorganização da massa do solo, em função das mudanças de umidade (Gunal \& Ransom, 2006). A birrefringência, que identifica os argilãs de estresse, é observada nas lâminas pela ocorrência da cor amarelada sob luz plana. Oliveira (1999) também observou a frequente ocorrência de argila formada por pressão (argilãs de estresse) em Cambissolo. Os argilãs de estresse são caracterizados pela forte birrefringência, que confere aos solos o aspecto brilhante, visível no campo como cerosidade (Embrapa, 2006). Segundo Oliveira (1999), os argilãs de estresse ocorrem em função das mudanças de umidade, que proporcionam aumento da massa do solo, exercendo uma pressão, que será responsável pelo rearranjamento das partículas na superfície das unidades estruturais. A elevada frequência de argilãs de estresse nos perfis da topossequência indica que a cerosidade identificada no campo pode ser, em maior parte, consequência destes. 


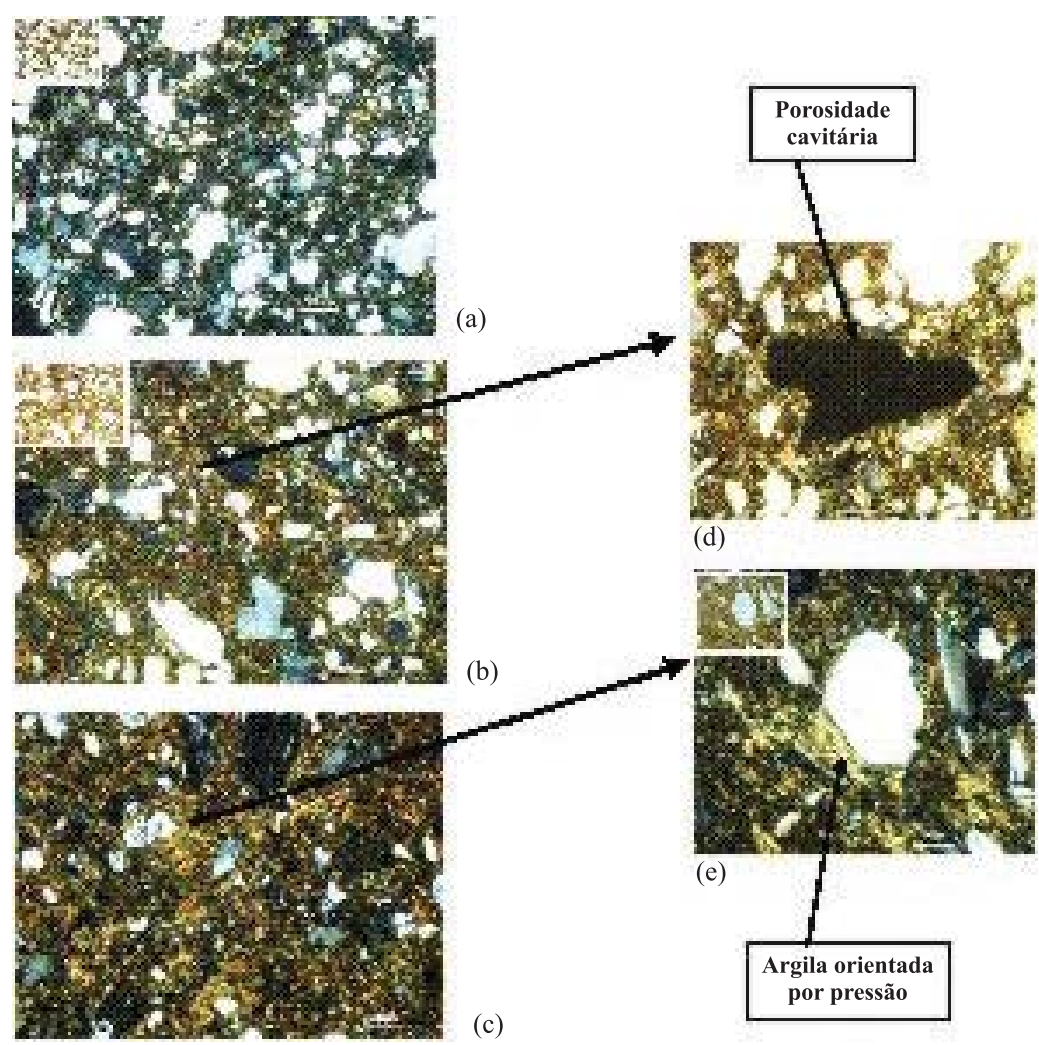

Figura 6. Fotomicrografias (XPL) dos horizontes BA, Bt1 e Bt2 do perfil P4, com detalhes sob luz PPL: (a) fundo matricial do horizonte BA com trama porfírica de espaço simples; (b) fundo matricial do horizonte Bt1 com trama porfírica de espaço simples; (c) fundo matricial do horizonte Bt2 com trama porfírica fechada; (d) poros do tipo cavidade observada no horizonte Bt1; (e) fábrica birrefringente do horizonte Bt1.

As feições pedológicas destacadas nos solos da topossequência são: (a) revestimentos típicos de poros, ocasionais, com orientação moderada a forte; (b) preenchimentos ocasionais, densos, de orientação moderada; e (c) nódulos de Fe, raros, típicos, com impregnação moderada e bordas nítidas a claras. Possivelmente a pequena expressão das feições pedológicas indicativas de processo de iluviação observadas deve-se ao fato de o fundo matricial estar recoberto por mica, o que dificulta essa observação. Entretanto, os argilãs de iluviação são observados em alguns pontos do no perfil P3 (Figura 11). Diante desse fato, não se pode afirmar que os resultados micromorfológicos dos perfis $\mathrm{P} 2$ e $\mathrm{P} 4$ confirmam a ocorrência do processo pedogenético de eluviação e iluviação. Nestes perfis, a acumulação de argila no horizonte $\mathrm{B}$ pode ser decorrente da remoção seletiva de argila nos horizontes superficiais.

\section{Gênese e classificação}

Quanto à gênese e classificação dos perfis, todos possuem horizonte diagnóstico superficial A moderado. $\mathrm{O}$ perfil P1 apresentou horizonte diagnóstico subsuperficial B incipiente, sem evidência de processo pedogenético predominante, sendo classificado como
Cambissolo Háplico Tb distrófico típico devido à baixa atividade da argila e ao $\mathrm{V}<50 \%$. Para esse perfil, acredita-se que a estratificação do material de origem, com bandeamentos de minerais mais resistentes, como o quartzo, conduziu a diferentes níveis de resistência ao intemperismo do gnaisse na paisagem. Esse fator, associado a diferentes ângulos de exposição do gnaisse, pode ter dificultado a pedogênese intensa, contrapondose ao efeito da topografia plana, onde se localiza o perfil P1.

O perfil P2 apresentou gradiente textural de 1,9, associado à presença de argilas de atividade baixa (Tb), atendendo às exigências para a identificação de horizonte B textural, sendo classificado como Argissolo. O predomínio de cores com matiz 10YR e 7,5 YR nos primeiros $100 \mathrm{~cm}$ do horizonte $\mathrm{B}$, associado a valores de $\mathrm{V} \%<50$, define o P2 como Argissolo Vermelho-Amarelo distrófico típico. Nesse solo, a declividade foi determinante para a remoção seletiva de argila, contribuindo para a formação do gradiente textural.

No perfil P3, verifica-se a variação da textura do horizonte A para B, com pequeno acréscimo de argila no $\mathrm{B}$, sem caracterizar a ocorrência de um gradiente textural para classificá-lo como Argissolo. O grau de 
desenvolvimento da cerosidade não foi suficiente para identificar um horizonte B textural na seção de controle exigida, embora o conteúdo de argila aumente em profundidade. Por apresentar um horizonte B incipiente, o perfil foi classificado como Cambissolo Háplico. Este solo apresenta textura superficial franco-argiloarenosa, $\mathrm{pH}$ ligeiramente ácido, com mineralogia predominante de caulinita, mas com presença de illita e ocorrência de feldspatos no perfil do solo, evidenciando menor grau de evolução pedogenética. Acredita-se que a forma retilínea, nesta seção da topossequência, associada à elevada declividade (116 \%), tenha facilitado o processo erosivo, retardando a evolução do solo nesse ponto. Segundo Derpsch et al. (1991), o aumento da declividade indica maior possibilidade de ocorrência de processos erosivos. Este perfil, por apresentar baixa atividade da argila e $\mathrm{V}<50 \%$, foi classificado como Cambissolo Háplico Tb distrófico típico.

$\mathrm{O}$ perfil $\mathrm{P} 4$, localizado no terço inferior da topossequência, apresentou incremento de argila, definido por relação B/A de 1,8 , identificando o horizonte B textural. A superfície côncava nesse ponto da topossequência contribuiu para o maior fluxo horizontal de água, intensificando a remoção de argila, caracterizada em P4 pelo gradiente textural. Nos horizontes subsuperficiais, o predomínio do matiz 10 YR e o V > 50 \% definiram o perfil P4 como Argissolo Amarelo eutrófico típico.

O perfil P5 foi classificado como Gleissolo Háplico, localizado na área plana de várzea, e teve favorecidas as condições de hidromorfia, conduzindo à formação de estrutura maciça e cores acinzentadas no horizonte $\mathrm{Cg}$, expressando o predomínio do processo de gleização. Devido à baixa atividade da argila e ao $\mathrm{V}<50 \%$ até 1,0 m, o perfil foi classificado como Gleissolo Háplico $\mathrm{Tb}$ distrófico típico.

\section{CONCLUSÕES}

1. Os perfis foram caracterizados por apresentarem argila de baixa atividade, com domínio de caulinita, relação ki menor que 2,0 e silte/argila < 0,7 na maior parte dos horizontes subsuperficiais. Apesar de esses atributos identificarem um grau de pedogênese mais elevado, alguns aspectos morfológicos, os baixos valores de Fed e a presença de illita indicam menor grau de alteração e de maturidade pedogenética.

2. Nos perfis que ocorrem nas partes mais altas da topossequência, a remoção seletiva de argila é um processo pedogenético evidente e significativo. Para o localizado na área de várzea, verifica-se a gleização como o principal processo. Em ambos os processos destaca-se a ação do fator relevo, favorecendo a translocação e, ou, remoção de argila e condicionando o hidromorfismo.
3. O relevo e o material de origem gnáissico estratificado foram os principais fatores que atuaram na gênese dos solos estudados no ambiente de Mar de Morros.

\section{LITERATURA CITADA}

AB'SABER, A. Domínios morfoclimáticos e solos do Brasil. In: ALVAREZ V., V. H.; FONTES L.E.F. \& FONTES, M.P.F., eds. Os solos nos grandes domínios morfoclimáticos do Brasil e o desenvolvimento sustentável. Viçosa, MG, Sociedade Brasileira de Ciência do Solo/Universidade Federal de Viçosa, 1996. p.1-18.

ANJOS, L.H.C.; FERNANDES, M.R.; PEREIRA, M.G. \& FRANZMEIER, D.P. Landscape and pedogenesis of an Oxisol-Inceptisol-Ultisol sequence in Southeastern Brazil. Soil Sci. Soc. Am. J., 62:1651-1658, 1998.

BIRKELAND, P.W. Pedology, weathering and geomorphological research. New York, 1974. 285p.

BESOAIN, E. Mineralogía de arcillas de suelos. San José, Instituto Interamericano de Cooperacion para La Agricultura - IICA, 1985. 1205p. (Serie de Libros y Materiales Educativos, 60)

BOCKHEIM, J.G.; GENNADIYEV, A.N.; HAMMER, R.D. \& TANDARICH, J.P. Historical development of key concepts in pedology. Geoderma, 124:23-36, 2005.

BREWER, R. Fabric and mineral analysis of soil. New York, Robert E. Krieger, 1976. 428p.

BUOL, S.W.; HOLE, F.D. \& Mc CRAKEN, R.J. Soil genesis and classification. 2.ed. Ames, The Iowa State University Press, 1980. 406p.

BULLOCK, P.; FEDOROFF, N.; JONGUERIUS, A.; STOOPS, G. \& TURSINA, T. Handbook of soil thin section description. Wolverhampton, Waine Research Publication, 1985. 152p.

CAMPOS, M.C.C.; MARQUES JÚNIOR, J.; PEREIRA, G.T.; MONTANARI, R. \& CAMARGO, L.A. Relações solopaisagem em uma litossequência arenito-basalto na região de Pereira Barreto, SP. R. Bras. Ci. Solo, 31:519-529, 2007.

CHRISTOFOLETTI, A. Geomorfologia. 2.ed. São Paulo. Edgard Blucher, 1980. 188p.

CORRÊA, M. M.; KER, J. C.; MENDONÇA, E. S.; RUIZ, H. A. \& BASTOS, R. S. Atributos físicos, químicos e mineralógicos de solos da região das várzeas de Souza (PB). R. Bras. Ci. Solo, 27:311-324, 2003.

DERPSCH, R.; ROTH, C.H.; SIDIRAS, N. \& KOPKE, U. Controle da erosão no Paraná, Brasil: Sistemas de cobertura do solo, plantio direto e preparo conservacionista do solo. Eschborn, Deutsche Gesellschaff fur Technische Zusammenarbeit (GTZ), 1991. 272p.

DERRUAU, M. Précis de géomorphologie. 4.ed. Paris, Masson et Cie, 1965. 536p. 
DUCHAUFOUR, P. Pedology: Pedogenesis and classification. London, George Allen \& Unwin, 1982. 448p.

EMPRESA BRASILEIRA DE PESQUISA AGROPECUÁRIAEMBRAPA. Centro Nacional de Pesquisa do Solo. Manual de métodos de análises de solos. Rio de Janeiro, 1997. $212 \mathrm{p}$.

EMPRESA BRASILEIRA DE PESQUISA AGROPECUÁRIAEMBRAPA. Centro Nacional de Pesquisa do Solo. Sistema brasileiro de classificação de solos. Rio de Janeiro, 2006. 306 p.

FANNING, D.S. \& FANNING, M.C.B. Soil, morphology, genesis and classification. New York, John Whiley \& Sons, 1989. $395 p$.

FREIRE, O. Solos das regiões tropicais. Botucatu, FEPAF, 2006. 271p.

FIGUEIREDO, M.A.; VARAJÃO, A.F.D.C.; FABRIS, J.D.; LOUTFI, I.S. \& CARVALHO, A.P. Alteração superficial e pedogeomorfológia no sul do complexo Bação Quadrilátero Ferrífero (MG). R. Bras. Ci. Solo, 28:713729, 2004.

GHIDIN, A.A.; MELO, V.F.; LIMA, V.C. \& LIMA, J.M.J.C. Topossequência de Latossolos originados de rochas basálticas no Paraná. I- mineralogia da fração argila. R. Bras. Ci. Solo, 30:293-306, 2006.

HALLETT, R.B. \& KYLE, P.R. XRF and INAA determinations of major and trace elements in geological survey of Japan igneous and sedimentary rock standards. Geostandards Newsletter, 17:127-133,1993.

GIAROLA, N.F.B.; SILVA, A.P. \& IMHOFF, S. Relações entre propriedades físicas e características de solos da região Sul do Brasil. R. Bras. Ci. Solo, 26:885-893, 2002.

GUNAL, H. \& RANSOM, M.D. Clay illuviation and calcium carbonate accumulation along a precipitation gradient in Kansas. Catena, 68:59-69, 2006.

JENNY, H. Factors of soil formation: A system of quantitative. New York, McGraw-Hill, 1941. 271p.

KÄMPF, N. \& CURI, N. Óxidos de ferro: Indicadores de ambientes pedogênicos e geoquímicos. In: NOVAIS, R.N.; ÁLVAREZ V., V.H. \& SCHAEFER. C.E.G.R. Tópicos em ciências do solo. Viçosa, MG, Sociedade Brasileira de Ciência do Solo, 2000. p.107-138. v. I.

KÄMPF, N. \& CURI, N. Argilominerais em solos brasileiros. In: CURI, N.; MARQUES, J.J.G.S.M.; GUILERME, L.R.G.; LIMA, J.M.; LOPES, A.S. \& ALVAREZ V., V.H. Tópicos em ciências do solo. Viçosa, MG, Sociedade Brasileira de Ciência do Solo, 2003. v.3.p.1-54.

KÄMPF, N. Ferro no solo. In: Reunião sobre ferro em solos inundados, 1, Goiânia, 1988. Anais...Goiânia, 1988. p. 3571 .

LIMA, H.N.; MELLO, J.W.V.; SCHAEFER, C.E.G.R.; KER, J.C. \& LIMA, A.M.N. Mineralogia e química de três solos de uma topossequência da Bacia Sedimentar do Alto Solimões, Amazônia Ocidental. R. Bras. Ci. Solo, 30:5968, 2006.
MEHRA, O.P. \& JACKSON, M.L. Iron oxides removal from soils and clays by a dithionite-citrate-bicarbonate system buffered with sodium bicarbonate. Clays Clay Miner., 7:317-327, 1960 .

MILNE, G. Some suggested units of classification and mapping particularly for East African soils. Soil Res., 4:183-198, 1934.

MONTANARI, R.; MARQUEZ JÚNIOR, J.; PEREIRA, G.T. \& SOUZA, Z.M. Forma da paisagem como critério para otimização amostral de Latossolos sob cultivo de cana-deaçúcar. Pesq. Agropec. Bras., 40:69-77, 2005.

MOREAU, A.M.S.S.; KER, J.C.; COSTA, L.M. \& GOMES, F.H. Caracterização de solos de duas topossequências em tabuleiros costeiros do sul da Bahia. R. Bras. Ci. Solo, 30:1007-1019, 2006.

MOREIRA, F.L.M. Influência de atributos físicos, químicos e mineralógicos sobre a capacidade de adsorção de fósforo em solos do Estado do Ceará. Fortaleza, Universidade Federal do Ceará, 2000. 68p. (Tese de Mestrado)

MURPHY, C.P. Thin section preparation of soils and sediments. Berkhamsted, A.B. Academic Publishers, 1986. 149p.

NUMMER, A.R. Geometria e cinemática de alojamento do maciço granítico de Arrozal Sudoeste do Estado do Rio de Janeiro. São Paulo, Universidade de São Paulo, 2001. 171p. (Tese de Doutorado)

OLIVEIRA, J.A. Caracterização física da bacia do Ribeirão Cachimbal-Pinheiral (RJ) e de suas principais paisagens degradadas. Seropédica, Universidade Federal Rural do Rio de Janeiro. 1998. 142p. (Tese de Mestrado).

OLIVEIRA, C.V. Atributos químicos, mineralógicos e micromorfológicos, gênese e uso de solos do Projeto Jaíba, Norte de Minas Gerais. Viçosa, MG, Universidade Federal de Viçosa, 1999. 161p. (Tese de Doutorado)

PACHEPSKY, Y.A.; TIMLIN, D.J. \& RAWLS, W.J. Soil water retention as related to topographic variables. Soil Sci. Soc. Am. J., 65:1787-1795, 2001.

PROJETO RADAMBRASIL - RADAMBRASIL. Folhas S. 23/ 24. Levantamento de recursos naturais. Rio de Janeiro, 1983. v. 32. 775 p.

RESENDE, M.; CURI, N.; KER, J.C. \& REZENDE, S.B. Mineralogia dos solos brasileiros: Interpretação e aplicações. Lavras, Universidade Federal de Lavras, 2005. $192 \mathrm{p}$.

SANTOS, M.C. \& BATISTA, M. Avaliações física, química e mineralógica em solos plínticos da região meio-norte do Brasil, submetidos a teste de umedecimento e secagem. R. Bras. Ci. Solo, 20:21-31, 1996.

SANTOS, R.D.; LEMOS, R.C.; SANTOS, H.G.; KER, J.C. \& ANJOS, L.H.C. Manual de descrição e coleta de solo no campo. 5.ed. Viçosa, MG, SBCS/EMBRAPA/CNPS, 2005. $100 \mathrm{p}$.

SCHULZE, D.G. The influence of aluminum on iron oxides. VII. Unit-cell dimensions of Al-substituted goethites and estimation of $\mathrm{Al}$ from them. Clays Clay Miner., 32:27-39, 1984. 
SCHWERTMANN, U. Differenzierung der eisenoxide des bodens durch photochemische extraktion mit saurer ammoniumoxalate-Lösung. Z. Pflanzenernähr, 105:194$202,1964$.

SCHWERTMANN, U. \& TAYLOR, R.M. Iron oxides. In DIXON, J.B. \& WEED, S.B. Minerals in soil environments. 2.ed. Madison, Soil Science Society of America, 1989. p.379-438.

SILVA, M.B.; ANJOS, L.H.C.; PEREIRA, M.G \& NASCIMENTO, R.A.M. Estudo de topossequência na baixada litorânea fluminense: Efeito do material de origem e posição topográfica. R. Bras. Ci. Solo, 25:965976, 2001.

SIMONSON, R.W. Outline of a generalized theory of soil genesis. Soil Sci. Soc. Am. Proc., 22:152-156, 1959.
SIX, J.; BOSSUYT, H.; DEGRYZE, S. \& DENEF, K. A history of research on the link between (micro) aggregates, soil biota, and soil organic matter dynamics. Soil Tillage Res., 79:7-31, 2004

TROEH, F.R. Landform equations fitted to contour maps. Soil Sci. Soc. Am. J., 263:616-627, 1965.

VALLADARES, G.S. Formas de ferro como índices de pedogênese e adsorção de fósforo. Seropédica, Universidade Federal Rural do Rio de Janeiro, 2000. 133p. (Tese de Mestrado).

VIDAL-TORRADO, P.; MACIAS, F.; CALVO, R.; CARVALHO, S.G. \& SILVA, A.C. Gênese de solos derivados de rochas ultramáficas serpentinizadas no sudoeste de Minas Gerais. R. Bras. Ci. Solo, 30:523-541, 2006. 